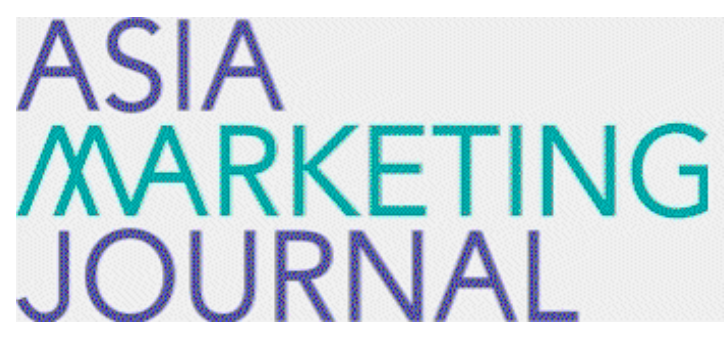

ASIA MARKETING JOURNAL

Volume 16 | Issue 1

Article 4

4-30-2014

\title{
Measuring the Impact of Competition on Pricing Behaviors in a Two-Sided Market
}

Min Kyung Kim

Ins Eong Song

Follow this and additional works at: https://amj.kma.re.kr/journal

Part of the Marketing Commons

\section{Recommended Citation}

Kim, Min Kyung and Song, Ins Eong (2014) "Measuring the Impact of Competition on Pricing Behaviors in a Two-Sided Market," Asia Marketing Journal: Vol. 16 : Iss. 1 , Article 4.

Available at: https://doi.org/10.53728/2765-6500.1527

This Article is brought to you for free and open access by Asia Marketing Journal. It has been accepted for inclusion in Asia Marketing Journal by an authorized editor of Asia Marketing Journal. 


\title{
Measuring the Impact of Competition on Pricing Behaviors in a Two-Sided Market*
}

\author{
Minkyung Kim** \\ Inseong Song***
}

The impact of competition on pricing has been studied in the context of counterfactual merger analyses where expected optimal prices in a hypothetical monopoly are compared with observed prices in an oligopolistic market. Such analyses would typically assume static decision making by consumers and firms and thus have been applied mostly to data obtained from consumer packed goods such as cereal and soft drinks. However such static modeling approach is not suitable when decision makers are forward looking. When it comes to the markets for durable products with indirect network effects, consumer purchase decisions and firm pricing decisions are inherently dynamic as they take into account future states when making purchase and pricing decisions. Researchers need to take into account the dynamic aspects of decision making both in the consumer side and in the supplier side for such markets. Firms in a two-sided market typically subsidize one side of the market to exploit the indirect network effect. Such pricing behaviors would be more prevalent in competitive markets where firms would try to win over the battle for standard. While such qualitative expectation on the relationship between pricing behaviors and competitive structures could be easily formed, little empirical studies have measured the extent to which the distinct pricing structure in two-sided markets depends on the competitive structure of the market. This paper develops an empirical model to measure the impact of competition on optimal pricing of durable products under indirect network effects.

In order to measure the impact of exogenously determined competition among firms on pricing, we compare the equilibrium prices in the observed oligopoly market to those in a hypothetical monopoly market. In computing the equilibrium prices, we account for the forward looking behaviors of consumers and supplier. We first estimate a demand function that accounts for consumers' forward-looking behaviors and indirect network effects. And then, for the supply side, the pricing equation is obtained as an outcome of the Markov Perfect Nash Equilibrium in pricing. In doing so, we utilize numerical dynamic programming techniques. We apply our model to a data set obtained from the U.S. video game console market. The video game console market is considered a prototypical case of two-sided

\footnotetext{
* This research has been supported by Institute of Management Research at Seoul National University. Inseong Song is the corresponding author.

** PhD Student, Yale School of Management(minkyung.kim@yale.edu)

*** Associate Professor, Seoul National University Business School(isong@snu.ac.kr)
} 
markets in which the platform typically subsidizes one side of market to expand the installed base anticipating larger revenues in the other side of market resulting from the expanded installed base. The data consist of monthly observations of price, hardware unit sales and the number of compatible software titles for Sony PlayStation and Nintendo 64 from September 1996 to August 2002. Sony PlayStation was released to the market a year before Nintendo 64 was launched. We compute the expected equilibrium price path for Nintendo 64 and Playstation for both oligopoly and for monopoly.

Our analysis reveals that the price level differs significantly between two competition structures. The merged monopoly is expected to set prices higher by $14.8 \%$ for Sony PlayStation and $21.8 \%$ for Nintendo 64 on average than the independent firms in an oligopoly would do. And such removal of competition would result in a reduction in consumer value by $43.1 \%$. Higher prices are expected for the hypothetical monopoly because the merged firm does not need to engage in the battle for industry standard. This result is attributed to the distinct property of a two-sided market that competing firms tend to set low prices particularly at the initial period to attract consumers at the introductory stage and to reinforce their own networks and eventually finally to dominate the market.

Key words: two-sided market, indirect network effect, merger, competition, pricing, numerical dynamic programming, video game console industry

\section{Introduction}

Shoppers prefer shopping malls with a variety of selection of retail stores and retailers want to open a store in a popular mall. Similarly, smartphone users decide to adopt a handset with an operating system that runs many applications and application developers are motivated to launch applications for a platform that is popular among users. In many industries, two types of participants interact through platforms and affect each other's decision about whether to join the platform or not. Such indirect network effect is a distinct property of two-sided markets. Indirect network effects are well exemplified in various two-sided markets such as shopping malls, video game consoles, and credit card payment system. Note that the indirect network effect would not require the same-side inter-consumer interaction such as word-of-mouth. Some markets are characterized by the presence of inter-consumer interaction. For example, consumer movie choice can be affected by other consumers' choice (Kim and Kim 2013). However the same side inter-consumer interaction is not necessary in the twosided market. What matters is the indirect network effect that occurs across markets. Due to the indirect network effects, firms in a twosided market have an incentive to invest to accumulate the installed base in the early period 
of the market. Major portion of such investment takes the forms of subsidy to one side of the market. That is, firms typically subsidize one side of market by lowering the prices to increase the size of the installed base. A larger installed base would increase the willingnessto-pay of the other side. It can be easily expected that the incentive for a platform to subsidize one side of the market is stronger when platforms compete each other. With strong indirect network effects, platforms are eager to win the battle for standard and thus have stronger incentive to increase its network size as early as possible. While such qualitative expectation on the impact of competitive pressure on firms' incentive to subsidize can be easily formed, little empirical research has been done to measure the extent of such impact.

Why is it important to measure the impact of competition on pricing? The issue of assessing competitive effects is important to both policy makers and managers. First, with such measures, one can assess the impact of a merger in an industry with indirect network externalities. The impact of mergers has been studied mostly for consumer packed goods. To our best knowledge, no formal research has provided a measure of the impact of competition, or merger equivalently, in a market with indirect network effect. Given the fundamental differences in demand and supply between consumer packed goods and platform products, existing approaches used for consumer packed goods may not be suitable for the cases for two-sided platforms. This study provides a formal procedure to measure the impact of competition on pricing in a two-sided market. Policy makers may utilize such assessment procedure when making decisions on merger approval in a two-sided market. Second, competition is of a great interest to managers. Managers want to figure out how their pricing decision should reflect competitive pressures. The approach used in this paper also gives a hint on how to incorporate competitive factors optimally in making pricing decisions for products with indirect network effects.

The impact of competition has been a major research issue in marketing and economics. One can assess the impact of a horizontal merger by comparing pricing behaviors of firms before and after a merger, if data are available. Kim and Song (2012) estimate the impact of a horizontal merger between manufacturers on channel pricing behaviors using a market data set obtained from toilette paper industry. By comparing the differences in model parameter estimates before and after the merger between Kimberly and Scott, they find that the merged manufacturer becomes tougher in pricing. Although such approach is desirable, researchers may suffer from the unavailability of data in many cases. In fact, marketers and policy makers want to know the impact of a merger before it really happens, because they need to make decision on whether to invest on a possible merger 
or whether to approve a proposed merger. An alternative approach has been utilized to overcome the data unavailability. In that approach, researchers first develop a structural model in which the model parameters represent policy invariant parameters. And the estimation results are applied to merger simulation analyses where equilibrium prices are computed for hypothetical merger case. Such approach has been adopted in many studies to investigate the impact of a possible merger in consumer packed goods such as the ready-to-eat cereal (Nevo 2000) and carbonated soft drinks (Dube 2005). For such products, the market conditions are expected to be stationary. Since the merger is not expected to produce any dynamics in such stationary market, the merger simulation is straightforward. However, the notion of the two-sided market explicitly recognizes the $\mathrm{dy}^{-}$ namic aspect of indirect network effects for both demand and supply side. Therefore, the existing approach for the merger analysis cannot be directly applied to two-sided markets.

Many two-sided platforms are durable products as is the case for video game console. It is well known that for durable products, consumers' strategic forward-looking buying behaviors are related to the shape of market level diffusion curve (Song and Chintagunta 2003). Accounting for such forward-looking behaviors requires a dynamic model setup. Previous studies in economics and marketing have developed structural models that account for consumers' forward looking behaviors and/or firms dynamic decisions on marketing activities reflecting such dynamics in the demand side. Existing studies have been successful in modeling such dynamic interaction between demand and supply. Recent studies have started to focus on the competition issue for durable product markets with indirect network effects. Those studies build dynamic structural models to investigate how the competitive market equilibrium evolves in twosided markets (Markovich and Moenius 2009, Dubé, Hitsch and Chintagunta 2010). However, to our best knowledge, little literature has been developed in formally measuring the extent to which the competitive structure affects the unique pricing structure in a two-sided market. This study tries to measure the impact of competition on pricing in a two-sided market. The idea itself is simple. We compare the expected equilibrium prices between two cases. In one case, the market is assumed to have competitive structures. In the other case, we assume that there exists a multi-product monopoly firm. By comparing equilibrium prices between two cases, we can measure the impact of competitive structure on pricing. We apply our idea to a data set obtained from video game console market. In the industry, there are two major players - Sony and Nintendo. Since the observed market is oligopoly, the monopoly case is a counterfactual case. In order for the comparison to be meaningful, we have to have estimates of structural parameters on demand 
and supply. Thus we develop an equilibrium model and obtain estimates of structural parameters and the parameter estimates are used as inputs to counterfactual analyses. The equilibrium model is derived from the interaction between the demand model that accounts for consumers' forward-looking behaviors and the supply side model that incorporates competitive dynamics in a two-sided market. We utilize the numerical framework developed by Dubé, Hitsch and Chintagunta (2010) to compute the equilibrium prices.

The results of our analysis indicate that the merged firm in the monopoly market is more likely to set higher prices than competing firms in the duopoly market do from the introduction stage. This is because the merged firm does not need to care about the initial advantage as much as the competing firms do. The competing firms in the duopoly market need to set lower prices to capture initial advantages in installed bases so that they can benefit from indirect network effects, finally to dominate the market.

The rest of this paper is organized as follows. In Section 2, we discuss the previous studies that explore the research problems on the market with indirect network effects and dynamic structural models. Section 3 describes the modeling framework that incorporates consumers' and firms' forward-looking behaviors to solve for equilibrium and to analyze the impact of competition on market outcomes. Section 4 briefly describes video game console industry data used in the study. Section 5 provides detailed explanations on the parameter estimation procedure, numerical simulation to compute the equilibrium along with the discussion of our results. Section 6 summarizes this study and suggests directions for future research.

\section{Literature Review}

Since the pioneering work by Katz and Shapiro (1985), there has been an extensive theoretical literature on two-sided markets incorporating indirect network effects. The studies by Caillaud and Jullien (2003) and Rochet and Tirole (2003) are among the pioneers in this area as they identify and characterize the indirect network effect that distinguishes the market from onesided markets and also describe the determinants of equilibrium prices. Subsequent studies extend the scope of research to various issues such as product strategies (Sun, Xie and Cao 2004), market leadership determinants (Nair, Chintagunta and Dubé 2004, Argentesi and Filistrucchi 2007, Tellis, Yin and Niraj 2009), market evolution (Gupta, Jain and Sawhney 1999, Markovich and Moenius 2009, Dubé, Hitsch and Chintagunta 2010) and pricing (Park 2004, Kaiser and Wright 2006, Liu 2010). The theoretical model by Godes, Ofek and Sarvary (2009) investigates the impact of competition among 
platforms on media firms' profits and actions. Their study examines the extent to which the unbalanced pricing strategy in media industry varies across the competition intensity. It compares the duopoly cases to the monopoly case to investigate how the competition affects media firm strategies in a two-sided context. Empirical studies utilize market data (see for example Nair, Chintagunta and Dubé 2004; Park 2004; Kaiser and Song 2006; Dubé, Hitsch and Chintagunta 2010; Liu 2010) or field experiments (Tucker and Zhang 2010). Table 1 clas- $^{-}$ sifies the studies in the two-sided market literature based on product types and main research issues. In terms of modeling, durable goods markets and non-durable goods markets differ in extent to which consumers engage in forward-looking behaviors regarding the deci- sions to join the platform.

There is extensive literature that models decision makers' dynamic behaviors formally. Such studies focus on incorporating the role of consumers' and firms' beliefs and on purchase and marketing decisions. According to Chintagunta, Erdem, Rossi and Wedel (2006), dynamic structural models contain three common components: 1) time and uncertainty, 2) decision makers' objective functions and current information available, and 3) multi-period objective functions to be maximized. That is, decision makers get the information on the current choice set and make decision to maximize their expected utilities given the information available. Rust (1987) utilizes a nested fixed point algorithm to solve a stochastic discrete choice dynamic programming problem and applies the model to

〈Table 1〉 Studies on Two-sided Markets

\begin{tabular}{|c|c|c|}
\hline Industry & Topics & Studies \\
\hline \multirow{3}{*}{ General } & Platform Competition & $\begin{array}{l}\text { Katz and Shapiro (1985), Caillaud and Jullien (2003), Rochet } \\
\text { and Tirole (2003), Armstrong (2006) }\end{array}$ \\
\hline & Product Strategy & Sun, Xie and Cao (2004) \\
\hline & Market Identification & Rochet and Tirole (2006) \\
\hline \multirow[t]{2}{*}{ Durables } & Market Evolution & $\begin{array}{l}\text { Gupta, Jain and Sawhney (1999), Markovich and Moenius } \\
(2009)^{1 \mathrm{c}} \text {, Dubé, Hitsch and Chintagunta }(2010)^{1 \mathrm{a},} \text { 1c }^{2} \text {, Nair, } \\
\text { Chintagunta and Dubé }(2004)^{1 \mathrm{a}} \text {, Tellis, Yin and Niraj }(2009)^{1 \mathrm{a}}\end{array}$ \\
\hline & Pricing & Park $(2004)^{1 \mathrm{a}, 1 \mathrm{c}}, \mathrm{Liu}(2010)^{1 \mathrm{a}, 1 \mathrm{c}}$ \\
\hline \multirow{4}{*}{ Consumables $^{1 \mathrm{~b}}$} & Platform Competition & Godes, Sarvary and Ofek (2009) \\
\hline & Pricing & Kaiser and Wright (2006) \\
\hline & Market Evolution & Argentesi and Filistrucchi (2007) \\
\hline & Advertising Effect & Kaiser and Song (2006), Tucker and Zhang (2010) \\
\hline
\end{tabular}

\footnotetext{
1a. empirically measures the size of indirect network effects compared to quality effects

1b. mostly includes advertising-supported media industries

1c : incorporates consumers' and /or firms' forward-looking behaviors
} 
the replacement behavior of bus engines. However, the curse of dimensionality is raised as a limitation of the nested fixed point procedure and several studies have tried to relieve the dimensionality problem. One of popular approaches to overcome the curse of dimensionality is the conditional choice probabilities approach suggested by Hotz and Miller (1993) that establishes the existence of a one-to-one mapping between the conditional valuation functions for the dynamic problem and their associated conditional choice probabilities.

Dynamic models of forward-looking behaviors have been used extensively for studying various topics in marketing such as adoption of a new product, purchase decision for consumer packed goods, effect of learning, and market evolution. Table 2 tries to summarize major re- search issues explored by marketing studies on dynamic models. In dynamic models, researchers need to make explicit assumption on what components decision makers are uncertain about. For example, consumers may be uncertain about the promotion timing of the product and may form expectations on the chance of promotional events. Similarly firms may face uncertainty on the level of demand and thus form expectations on distribution of future demands. Such modeling of expectation of decision makers is a core component of a dynamic model. Table 3 classifies the studies of forward-looking behaviors based on components decision makers are uncertain about. Some of them build dynamic structural demand models to explain consumers' forward-looking behaviors and others account for both consumers' and firms' dynamic

〈Table 2〉 Topics in Studies of Forward-looking Behaviors

\begin{tabular}{|c|c|}
\hline Topic & Studies \\
\hline Learning & Erdem and Keane1996) ${ }^{2 a}$, Ackerberg $(2003)^{2 a}$ \\
\hline Consideration Set and Search Cost & Mehta, Rajiv and Srinivasan $(2003)^{2 a}$ \\
\hline Purchase Incidence / Timing & Gönül and Srinivasan $(1996)^{2 a}, \operatorname{Sun}(2005)^{2 a}$ \\
\hline Brand Choice/Switching & $\begin{array}{l}\text { Sun, Neslin and Srinivasan }(2003)^{2 a} \text {, Erdem, Keane and Strebel }(2005)^{2 a} \text {, } \\
\text { Sun }(2005)\end{array}$ \\
\hline New Product Adoption & Song and Chintagunta $(2003)^{2 a}$ \\
\hline R\&D, Product Innovation & Goettler and Gordon $(2011)^{2 b}$ \\
\hline Product Replacement & Rust $(1987)^{2 a}$, Gordon $(2009)^{2 a}$ \\
\hline Product Launch and Exit & $\operatorname{Hitsch}(2006)^{2 c}$ \\
\hline Consumer Inventory & Erdem, Imai and Keane $(2003)^{2 a}$, Hendel and Nevo $(2006)^{2 a}$ \\
\hline Pricing & Nair $(2007)^{2 b}, \operatorname{Liu}(2010)^{2 \mathrm{c}}$ \\
\hline Market evolution & Markovich and Moenius (2009) ${ }^{2 a}$, Dubé, Hitsch and Chintagunta $(2010)^{2 b}$ \\
\hline
\end{tabular}


〈Table 3〉 Uncertainty Components in Studies of Forward-looking Behaviors

\begin{tabular}{ll}
\hline \multicolumn{1}{c}{ Uncertainty components } & \multicolumn{1}{c}{ Studies } \\
\hline Promotion expectation & Gönül and Srinivasan(1996), Sun, Neslin and Srinivasan(2003), Sun(2005), \\
\hline Price expectation & $\begin{array}{l}\text { Erdem, Imai and Keane(2003), Nair(2007), Mehta, Rajiv and } \\
\text { Srinivasan(2003), Hendel and Nevo(2006) }\end{array}$ \\
\hline Quality expectation & $\begin{array}{l}\text { Rust(1987), Erdem and Keane(1996), Ackerberg(2003), Markovich and } \\
\text { Moenius(2009), Goettler and Gordon(2011) }\end{array}$ \\
\hline Price and Quality expectation & Song and Chintagunta(2003), Erdem, Keane and Strebel(2005), Gordon(2009) \\
\hline Demand expectation & $\begin{array}{l}\text { Hitsch(2006), Markovich and Moenius(2009), Liu(2010), Goettler and } \\
\text { Gordon(2011) }\end{array}$ \\
\hline Price and Demand expectation & Dubé, Hitsch and Chintagunta(2010) \\
\hline
\end{tabular}

behaviors and solve for market equilibrium.

Closely related to our research, Liu (2010) and Dubé, Hitsch and Chintagunta (2010) integrate these two research streams and explore marketing issues in a two-sided market by formulating dynamic structural models. Liu (2010) analyzes whether video game console firms have incentives for price skimming or price penetration by studying a dynamic pricing game between firms under indirect network effects, consumer heterogeneity and oligopolistic competition between platforms. He estimates the model parameters and uses the estimation results to numerically solve for the Markov Perfect Equilibrium. Then he simulates the market evolution by using the obtained equilibrium on two firms' pricing policies and concludes that video game console industry follows the skimming price pattern. His approach is also used to compute the biases when either network effects, consumer heterogeneity, or dynamic pricing decision is not incorporated into the model and assesses the impact of key components in the framework. His paper also measures the degree of indirect network effects relative to that of price-quality effects and provides various policy simulations.

Dubé, Hitsch and Chintagunta (2010, DHC hereafter) measure tipping or market dominance induced by the indirect network effect in a durable market where forward-looking consumers and forward-looking firms interact. Their study quantifies the degree of tipping and also provides an elaborate computational procedure to analyze forward-looking agents' behaviors in a two-sided market. While our study has a very different research objective from $\mathrm{DHC}$, we utilize the computational procedure described in DHC to numerically compute the equilibrium prices in a two-sided market where both consumers and firms are forward-looking. And we modify the framework in the supply side to incorporate the hypothetical market structure (i.e. monopoly) as well as the observed market struc- 
ture (i.e. duopoly). Such an inclusion of hypothetical market structure is needed to measure the impact of competition on pricing in a twosided market. In the monopoly case, the merged firm would coordinate marketing activities for multiple brands in order to maximize the firm level value, which would lead to different pricing behaviors from the oligopoly case.

One might argue if it is important to measure the impact of competition on pricing, using existing methodological framework, especially where it is well expected that a monopoly would result in higher prices than a duopoly would do. We believe such measurement has academic values under the tradition of new empirical industrial organization. For example, Nevo(2000) measures the impact of possible mergers in the cereal market on market prices, using the methodological approach developed by Berry, Levinshon, and Pakes (1995). Dube (2005) also measures the impact of possible mergers in the soft drink industry, using the econometric modeling approach developed by Hendel (1999). Our study measures the impact of market structure on pricing but it differentiated from previous merger studies such as Nevo (2000) and Dube (2005) in the sense that we need to take into account the market evolution in the two-sided market unlike the their studies. That is why we utilize the modeling framework developed by $\mathrm{DHC}$.

\section{Model}

\subsection{Indirect Network Effects}

Video game console market is a prototypical two-sided market with indirect network effects. The structure of the market for video game consoles (hardware) and game titles (software) is general enough so it can be easily applied to another two-sided market with a platform and its complementary products. We use an equilibrium modeling framework developed by DHC. We assume that a game title is compatible with only one type of consoles, which is the case in the industry. We interchangeably use the word "platform" with console. The game titles compatible with platform $j$ at time $t+1$ target consumers who have purchased the platform $\mathrm{j}$ up to period $t$. Therefore, software provision is determined by the number of consumers who own the corresponding hardware. This notion of the indirect network effect between game provision and hardware demand is modeled by a standard log-log model as depicted in equation (1).

$$
\ln \left(n_{j t}\right)=\kappa_{j}+\varphi_{j} \ln \left(y_{j, t+1}\right)+v_{j t}
$$

where $n_{j t}$ is the number of software titles that are compatible with platform $j$ at time $t$ and $y_{j t}$ is the cumulative share of platform js installed hardware base at time $t$. 


\subsection{Consumer Decision}

Consumers' utility for a hardware alternative is derived from the benefit of available software in the market. In evaluating a hardware option, forward-looking consumers consider not only current software availability for that hardware but also the present value of future software availability for the platform. Since the future software provision is a function of the future installed base as depicted in equation (1), those consumers make expectations on the evolution of the installed base in order to assess the utility associated with the purchase of a particular hardware option. Thus, the state space comprises of the installed base of hardware alternatives. The evolution of the vector of the installed hardware bases is given by the following equation.

$$
\mathrm{y}_{\mathrm{t}+1}=\mathrm{f}^{\mathrm{e}}\left(\mathrm{y}_{\mathrm{t}}, \xi_{\mathrm{t}}\right)
$$

where $\xi_{j t}$ is the platform $j$ specific demand shock at time t, which is unknown to its competitors until its sales is realized, is independent and identically distributed across time and has the probability density function of $\phi_{j}(\bullet)$. Consumers also expect that hardware firms set prices using information on expected installed bases and platform specific demand shock as follows:

$$
\mathrm{p}_{\mathrm{jt}}=\sigma_{\mathrm{j}}^{\mathrm{e}}\left(\mathrm{y}_{\mathrm{t}}, \xi_{\mathrm{jt}}\right)
$$

Since the software provision is a function of installed hardware base, the software value is expressed as a function of the installed base as follows.

$$
\omega_{\mathrm{j}}\left(\mathrm{y}_{\mathrm{t}+1}\right)=E\left[\sum_{k=0}^{\infty} \beta^{k} u_{j}\left(y_{j, t+k+1}\right) \mid y_{t+1}\right]
$$

where $\beta$ is the discount factor for consumers and $\mathrm{u}_{\mathrm{j}}(\bullet)$ is per-period utility. The value can be computed recursively based on Bellman equation as follows.

$$
\begin{aligned}
\omega_{\mathrm{j}}\left(\mathrm{y}_{\mathrm{t}+1}\right)= & u_{j}\left(y_{j, t+1}\right) \\
& +\beta \int \omega_{\mathrm{j}}\left(\mathrm{f}^{\mathrm{e}}\left(\mathrm{y}_{\mathrm{t}+1}, \xi\right)\right) \phi(\xi) \mathrm{d} \xi
\end{aligned}
$$

Consumers compare the choice-specific value of purchase and value of waiting to make a choice decision. The value of purchasing platform $j$ at time $t$ is given by

$$
\begin{aligned}
v_{\mathrm{j}}\left(\mathrm{y}_{\mathrm{t}}, \xi_{\mathrm{t}}, \mathrm{p}_{\mathrm{t}}\right)+\epsilon_{\mathrm{jt}}= & \delta_{\mathrm{j}}+\omega_{\mathrm{j}}\left(\mathrm{f}^{\mathrm{e}}\left(\mathrm{y}_{\mathrm{t}}, \xi_{\mathrm{t}}\right)\right) \\
& -\alpha \mathrm{p}_{\mathrm{jt}}+\xi_{\mathrm{jt}}+\epsilon_{\mathrm{jt}}
\end{aligned}
$$

where $\delta_{j}$ is the intrinsic preference for platform $\mathrm{j}, \alpha$ is marginal utility of income or price sensitivity, and $\epsilon_{j t}$ is an iid type 1 extreme value random term to account for unobservable individual consumer specific utility. This assumption of type 1 extreme value distribution leads to closed form logit choice probability expressions for market shares. If a consumer does not buy any platform, the consumer forgoes consumption in that period and will choose the 
best alternative in the next period. Thus the value of delaying the purchase is denoted as

$$
\begin{aligned}
& v_{0}\left(\mathrm{y}_{\mathrm{t}}, \xi_{\mathrm{t}}\right)+\epsilon_{0 \mathrm{t}}=\beta \int \max \left\{v_{0}\left(\mathrm{y}_{\mathrm{t}+1}, \xi_{\mathrm{t}}\right)\right. \\
& \left.+\epsilon_{0, \mathrm{t}+1}, \max \left\{v_{\mathrm{j}}\left(\mathrm{y}_{\mathrm{t}+1}, \xi, \sigma^{\mathrm{e}}\left(\mathrm{y}_{\mathrm{t}+1}, \xi_{\mathrm{jt}}\right)\right)+\epsilon_{\mathrm{j}, \mathrm{t}+1}\right\}\right\} \\
& \phi_{\epsilon}(\epsilon) \phi(\xi) \mathrm{d}(\epsilon, \xi)+\epsilon_{0 \mathrm{t}}
\end{aligned}
$$

In the expression, the value of purchase delay, apart from the type 1 extreme value distributed random term, is given by the discounted expected maximum utility that can be obtained in the next period. Then, the market share of platform $\mathrm{j}$ is given by the logit formula as follows:

$$
s_{j}\left(y_{t}, \xi_{t}, p_{t}\right)=\frac{\exp \left(v_{j}\left(y_{t}, \xi_{t}, p_{t}\right)\right)}{\exp \left(v_{0}\left(y_{t}, \xi_{t}\right)\right)+\sum_{k=1}^{J} \exp \left(v_{k}\left(y_{t}, \xi_{t}, p_{t}\right)\right)}
$$

Given the market share, the installed base evolution in equation (2) can be rewritten as follows.

$$
\begin{aligned}
y_{j, t+1} & =y_{j t}+\left(1-\sum_{k=1}^{J} y_{k t}\right) s_{j}\left(y_{t}, \xi_{t}, p_{t}\right) \\
& =f_{j}\left(y_{t}, \xi_{t}, p_{t}\right)
\end{aligned}
$$

\subsection{Firm Decision}

The major difference between our study and DHC lies in firm decision. This study is interested in the impact of exogenous competitive structure on pricing. The main quantity of in- terest is the price differential across different competitive structures. We posit two market structures. One is the real market structure that the data are obtained from. It is a duopoly market in which Sony and Nintendo are considered to act independently. The other is a hypothetical market structure in which only one firm produces both Playstation and Nintendo 64. By comparing the pricing behavior of the merged firm in the hypothetical monopoly with the pricing behaviors of independently competing firms, we can assess the impact of competitive structure on pricing. So, unlike $\mathrm{DHC}$, our study considers two market structures that might result in different pricing behaviors.

\subsubsection{Oligopoly}

Suppose J platforms compete in the market and consumers single-home or, in other words, choose at most one platform in the whole period. Consumers are assumed to make rational expectations on the firms' policy function and consumer expectations are unbiased. Thus consumer expectation in equation (3) is assumed to be the same as the true pricing policy.

$$
p_{j}=\sigma_{j}\left(y, \xi_{j}\right)
$$

Firms are also assumed to expect rationally, so they anticipate that consumer side market will evolve based on equations (9). Platform js per-period profit function is given by 


$$
\begin{aligned}
& \pi_{j}\left(\mathrm{y}, \xi_{j}, p_{j}\right)=\left(p_{j}-c_{j}\right) \cdot\left(1-\sum_{k=1}^{J} y_{k t}\right) \\
& \cdot \int s_{j}\left(y, \xi_{j}, \xi_{-j}, p_{j}, \sigma_{-j}\left(y, \xi_{-j}\right)\right) \phi_{j}\left(\xi_{-j}\right) d \xi_{-j} \\
& +r_{j} \int q_{j}\left(f_{j}\left(y, \xi_{j}, \xi_{-j}, p_{j}, \sigma_{-j}\left(y, \xi_{-j}\right)\right)\right) \\
& \phi_{j}\left(\xi_{-j}\right) d \xi_{-j}
\end{aligned}
$$

where $c_{j}$ is the marginal cost of production, $r_{j}$ is the royalty rate from software suppliers, $q_{j}\left(y_{t+1}\right)$ is the number of software titles sold at time $\mathrm{t}$ and $\sigma_{-j}\left(y, \xi_{-j}\right)$ is the policy function of firms other than firm $j$. Note that the hardware manufacturer's profit consists of the sales profit from end-users and the royalty fees from game developers. Then the expected present value of profit for platform $\mathrm{j}$ is written by

$$
\begin{aligned}
& V_{j}\left(y_{t}, \xi_{t} \mid \sigma\right)=E\left\{\sum_{k=0}^{\infty} \beta_{f}{ }^{k} \pi_{j}\right. \\
& \left.\left(\mathrm{y}_{t+k+1}, \xi_{j, t+k+1}, \sigma_{j}\left(\mathrm{y}_{t+k+1}, \xi_{j, t+k+1}\right)\right) \mid y_{t}, \xi_{t}, \sigma\right\}
\end{aligned}
$$

where $\beta_{f}$ is the discount factor of hardware firms and $\sigma$ is the vector of price policies of $\mathrm{J}$ firms. Firm $\mathrm{j}$ will choose the policy function that maximizes the equation (12) and the value function can be expressed in Bellman equation as in the following equation.

$$
\begin{aligned}
V_{j}\left(y, \xi_{j}\right)= & \sup \left\{\pi_{j}\left(y, \xi_{j}, p_{j}\right)+\beta_{f} \int V_{j}\right. \\
& \left(f\left(y, \xi_{j}, \xi_{-j}, p_{j}, \sigma_{-j}\left(y, \xi_{-j}\right)\right), \xi_{j}^{\prime}\right) \\
& \left.\phi\left(\xi_{-j}\right) \phi\left(\xi_{j}^{\prime}\right) d\left(\xi_{-j}, \xi_{j}^{\prime}\right)\right\}
\end{aligned}
$$

\subsubsection{Monopoly}

In order to figure out the effect of competition on pricing, we consider a hypothetical case where competing firms are merged to a monopoly firm offering $\mathrm{J}$ different hardware products. The merged firm has the following profit function.

$$
\begin{aligned}
\pi(\mathrm{y}, \xi, p)= & \sum_{k=1}^{J}\left[\left(p_{k}-c_{k}\right) \cdot\left(1-\sum_{k=1}^{J} y_{k t}\right)\right. \\
& \cdot s_{k}\left(y, \xi_{k}, p_{1}, p_{2}, \ldots, p_{J}\right)+r_{k} \\
& \left.\cdot q_{k}\left(f_{k}\left(y, \xi, p_{1}, p_{2}, \ldots, p_{J}\right)\right)\right]
\end{aligned}
$$

where $\xi_{k}$ is the demand shock specific for platform k. Then Bellman equation is given as

$$
\begin{aligned}
& \mathrm{V}(\mathrm{y}, \xi)=\sup \{\pi(\mathrm{y}, \xi, p)+\mid \\
& \left.\beta_{\mathrm{f}} \int \mathrm{V}\left(\mathrm{f}\left(\mathrm{y}, \xi, p_{1}, p_{2}, \ldots, p_{J}\right), \xi^{\prime}\right) \phi\left(\xi^{\prime}\right) \mathrm{d}\left(\xi^{\prime}\right)\right\}(15)
\end{aligned}
$$

\subsection{Equilibrium}

Given the behaviors of software suppliers, consumers and console firms, we solve for Markov Perfect Equilibrium in which the strategies depend only on the payoff-relevant information. Consumers and firms are assumed to expect and act rationally so that their expectations and realized actions are mutually consistent.

\section{Data}

We apply our model to a market data set 
obtained from the video game console industry in the United States, provided by NPD Techworld's point of sales database. The data consist of monthly observations of price, hardware unit sales and the number of compatible software titles for Sony PlayStation and Nintendo 64 from September 1996 to August 2002. Sony PlayStation was released to the market a year before Nintendo 64 was launched. This data set was also used in other marketing studies such as Liu (2010) and Dubé, Hitsch and Chintagunta (2010). Table 4 presents descriptive statistics. The sales volumes indicate that Playstation is more popular than Nintendo 64 . Such popularity is also exemplified in the number of software titles available. In terms of prices, two platforms are not different much. The variabilities are large, mostly due to the nonstationarity in the data series.

In addition to the sales data, we obtain the producer price indices (PPIs) from the U.S. Bureau of Labor Statistics for computers, computer storage devices, and audio/video equipment to control for technology costs. We also collect the information on the exchange rate (JPY per USD) to control for the costs asso- ciated with the imported console parts. We also include in the set of exogenous variables a time trend to account for declining marginal production costs for platforms. And monthly fixed effects are used to control for seasonal demand and price peaks. The time trend and monthly fixed effects are also considered to drive the demand variation and thus included in demand models. And all the exogenous variables - time trend, monthly fixed effects, PPIs and exchange rates - are considered to affect costs and therefore included in price functions.

\section{Estimation and Simulation}

\subsection{Demand Estimation}

Our model explicitly recognizes price endogeneity. The unobserved shock in the demand reflected in the value function in equation (6) also appears in pricing function shown in equation (3). So prices and the unobserved shocks are correlated in the value function equation (6). The standard estimation of the model parame-

〈Table 4〉 Descriptive Statistics of Monthly Data

\begin{tabular}{ccccc}
\hline & \multicolumn{2}{c}{ Sony PlayStation } & \multicolumn{2}{c}{ Nintendo 64 } \\
\cline { 2 - 5 } & Mean & Std. dev. & Mean & Std. dev. \\
\hline Hardware Sales & 275,127 & 288,832 & 195,545 & 200,403 \\
Hardware Prices & 122 & 31 & 120 & 34 \\
Software Variety & 697 & 335 & 156 & 105 \\
\hline
\end{tabular}


ters in log-odds obtained by inverting the share equation (8) would lead to biased estimates. In order to address the price endogeneity issue, we utilize the control function approach suggested by Petrin and Train (2010).

Dynamic structural models would incorporate consumers' belief on the evolution of state variables and the beliefs are typically estimated in a nested fixed point approach as illustrated in Rust(1987). That is, the solution to the consumers' dynamic adoption decision is nested within the demand estimation procedure. Such approach would involve discretizing the continuous state spaces in order to compute the consumers' dynamic choice outcome at each value of demand parameters. However, such approach methodology would naturally suffer from the curse of dimensionality and the state space in our application is large enough to lead to the curse of dimensionality. So we utilize a two-stage estimation framework suggested by Dube, Hitsch, and Chintagunta (2010) as described below.

\subsubsection{First Stage}

In the first stage of the two-step approach, we estimate the reduced form relationship between market outcome variables and state variables. That is, we estimate the software provision, firms' pricing policies and consumers' purchase decision with respect to installed hardware base of platforms and demand shocks in the market. First, the software provision func- tion is specified as

$$
\ln \left(n_{j t}\right)=\Delta\left(y_{j, t+1} ; \theta_{n}\right)+\eta_{j t}
$$

where $y_{j, t+1}$ is the platform js installed base at the beginning of time $\mathrm{t}+1$ and $\eta_{j t}$ is a normal random term, i.e., $\eta_{j t} \sim N\left(0, \sigma_{\eta}^{2}\right)$. econd, the firms' pricing policies are expressed in a reduced form as follows.

$$
\ln \left(p_{j t}\right)=\Psi\left(y_{j t}, y_{-j t}, z_{t}^{p} ; \theta_{p}\right)+\xi_{j t}
$$

where $y_{-j t}$ is the competitors' installed base at the beginning of time $t, z_{t}^{p}$ is the exogenous variables including time trend, monthly dummy variables, PPIs and exchange rates. The random error $\xi_{j t}$ follows a normal distribution, i.e., $\xi_{j t} \sim N\left(0, \sigma_{\xi}^{2}\right)$. The function $\Psi$ can take various forms and here we choose a quadratic function of the installed based as that specification fits data best.' Third, we estimate the consumers' purchase decision using the log-odds of market shares. Given the functional form for the market share in equation (8), the log-odds are given by the following equation:

$$
\begin{aligned}
& \mu_{j t}=\ln \left(s_{j t}\right)-\ln \left(s_{0 t}\right) \\
& =\ln \left(\frac{\exp \left(v_{j}\left(y_{t}, \xi_{t}, p_{t}\right)\right)}{\exp \left(v_{0}\left(y_{t}, \xi_{t}\right)\right)+\sum_{k=1}^{J} \exp \left(v_{k}\left(y_{t}, \xi_{t}, p_{t}\right)\right)}\right) \\
& -\ln \left(\frac{\exp \left(v_{0}\left(y_{t}, \xi_{t}, p_{t}\right)\right)}{\exp \left(v_{0}\left(y_{t}, \xi_{t}\right)\right)+\sum_{k=1}^{J} \exp \left(v_{k}\left(y_{t}, \xi_{t}, p_{t}\right)\right)}\right)+\varsigma_{j t} \\
& =v_{j}\left(y_{t}, \xi_{t}, p_{t}\right)-v_{0}\left(y_{t}, \xi_{t}, p_{t}\right)+\varsigma_{j t} \\
& =\mathrm{T}\left(y_{j t}, y_{-j t}, \xi_{j t}, \xi_{-j t}, z_{t}^{d} ; \theta_{\mu}\right)+\varsigma_{j t}
\end{aligned}
$$


Here, $z_{t}^{d}$ is the set of exogenous variables that affect consumers' purchase decisions including time trend and monthly fixed effects. The random measurement error $\varsigma_{j t}$ is assumed to follow a normal distribution, i.e., $\varsigma_{j t} \sim N\left(0, \sigma_{\varsigma}^{2}\right)$. As mentioned earlier, we include the control function to handle endogeneity in prices. Using the distributional properties of random measurement errors, we estimate parameters $\Theta=\left(\theta_{n}, \theta_{p}, \theta_{\mu}\right.$, $\sigma_{\xi}, \sigma_{\varsigma}$ ) by maximizing the likelihood function. The likelihood function to be maximized is given as follows.

$$
\begin{aligned}
& \ln \left(L(\Theta ; \eta, \xi, \varsigma)=\ln \left(\operatorname{Pr}\left(\eta ; \theta_{n}, \sigma_{\eta}\right)\right)\right. \\
& +\ln \left(\operatorname{Pr}\left(\xi ; \theta_{p}, \sigma_{\xi}\right)\right)+\ln \left(\operatorname{Pr}\left(\varsigma ; \theta_{\mu}, \sigma_{\varsigma}\right)\right. \\
& =\text { constant }-2\left(\ln \left(\sigma_{\eta}\right)+\ln \left(\sigma_{\xi}\right)\right. \\
& \left.+\ln \left(\sigma_{\varsigma}\right)\right)-\frac{1}{2 \sigma_{\eta}^{2}} \sum_{j=S, N} \sum_{t=1}^{T}\left(\ln \left(n_{j t}\right)-y_{j, t+1} * \theta_{n}\right)^{\bar{e}} \\
& -\frac{1}{2 \sigma_{\xi}^{2}} \sum_{j=S, N} \sum_{t=1}^{T}\left(\ln \left(p_{j t}\right)-\left(y_{j t}, y_{-j t}, z_{t}^{p}\right) * \theta_{p}\right)^{2} \\
& -\frac{1}{2 \sigma_{\varsigma}^{2}} \sum_{j=S, N} \sum_{t=1}^{T}\left(\ln \left(\mu_{j t}\right)\right. \\
& \left.-\left(y_{j t}, y_{-j t}, \xi_{j t}, \xi_{-j t}, z_{t}^{d}\right) * \theta_{\mu}\right)^{2}
\end{aligned}
$$

Here, the subscript j stands for product, i.e., j = Sony, Nintendo.
The estimation results from software supply function, pricing function and market share function are presented in Table 5, Table 6 and Table 7, respectively. As expected, from Table 5 , we find a significant and positive relationship between the software variety and the installed base of each platform. For the pricing, as presented in Table 6, it appears that price is positively related to own installed base and negatively related to competitor's installed based, which is intuitive. Firms would want to exploit the large value of own installed base by charging high prices and also to cope with the large value of competitor's installed base by lowering own price. Negative quadratic term indicates that such effect is concave. Consumer utility, as shown in Table 7, turns out to be positively related to both own installed base and competitor's installed base, which is intuitive as the utility of a brand is relative to the no-purchase option.

\subsubsection{Second Stage}

The parameter estimates obtained in the first stage are reduced form parameters. In order to assess the impact of competition on pricing, we

〈Table 5〉 Software Provision

\begin{tabular}{ccccc}
\hline & \multicolumn{2}{c}{ Sony PlayStation } & \multicolumn{2}{c}{ Nintendo 64 } \\
\cline { 2 - 5 } & Estimate & Std. error & Estimate & Std. error \\
\hline Intercept & 8.0549 & 0.0067 & 8.8035 & 0.0076 \\
$y_{j}$ & 0.7396 & 0.0028 & 1.6578 & 0.0028 \\
$\log \left(\sigma_{\eta}\right)$ & -1.8607 (Estimate) & & 0.0069 (Standard Error) \\
\hline
\end{tabular}


〈Table 6〉 Pricing Policies

\begin{tabular}{|c|c|c|c|c|}
\hline & \multicolumn{2}{|c|}{ Sony PlayStation } & \multicolumn{2}{|c|}{ Nintendo 64} \\
\hline & Estimate & Std. error & Estimate & Std. error \\
\hline Intercept & 7.0557 & 0.0222 & 6.4912 & 0.0216 \\
\hline YSony & 0.5255 & 0.3520 & -4.3989 & 0.3176 \\
\hline $\mathrm{Y}_{\text {Nintendo }}$ & -13.8021 & 0.5584 & 14.4230 & 0.6705 \\
\hline $\mathrm{y}_{\text {Sony }}^{2}$ & -1.8074 & 1.8098 & -4.1352 & 2.6410 \\
\hline $\mathrm{y}^{2}$ Nintendo & -2.1695 & 3.8213 & -0.9662 & 5.7801 \\
\hline Time & 0.0348 & 0.0000 & -0.0131 & 0.0001 \\
\hline January & -0.2185 & 0.0044 & 0.0875 & 0.0038 \\
\hline February & -0.1879 & 0.0041 & 0.0952 & 0.0034 \\
\hline March & -0.1805 & 0.0040 & -0.0093 & 0.0043 \\
\hline April & -0.1720 & 0.0036 & 0.1189 & 0.0038 \\
\hline May & -0.1418 & 0.0029 & 0.0854 & 0.0045 \\
\hline June & -0.1721 & 0.0028 & 0.0807 & 0.0041 \\
\hline July & -0.1230 & 0.0032 & 0.0733 & 0.0041 \\
\hline August & -0.2256 & 0.0036 & 0.0026 & 0.0039 \\
\hline September & -0.2279 & 0.0039 & -0.0597 & 0.0040 \\
\hline October & -0.2533 & 0.0060 & -0.0376 & 0.0041 \\
\hline November & -0.1467 & 0.0042 & -0.0051 & 0.0026 \\
\hline PPI1 ${ }^{6 a}$ & 0.1968 & 0.0530 & -0.1403 & 0.0621 \\
\hline $\mathrm{PPI} 2^{6 \mathrm{~b}}$ & 2.6621 & 0.0481 & 2.8525 & 0.0596 \\
\hline$P P I 3^{6 c}$ & -4.3662 & 0.0295 & -3.5104 & 0.0353 \\
\hline Exchange rate $1^{6 \mathrm{~d}}$ & 0.1194 & 0.0194 & -0.0869 & 0.0213 \\
\hline Exchange rate $2^{6 \mathrm{e}}$ & -0.1791 & 0.0091 & -0.6672 & 0.0143 \\
\hline$\sigma_{i}$ & -1.9652 & 0.0125 & -1.9652 & 0.0125 \\
\hline
\end{tabular}

Note. Producer Price Index for computers (6a), for computer storage devices (6b) and for audio/video equipment (6c) Note. JPY per USD exchange rates with 3 -month lags (6d) and with 7-month lags (6e)

need to have policy invariant structural parameters. In the second stage of the estimation, we estimate the structural parameters via a minimum distance procedure that matches simulated consumer choices to observed data. The structural parameters include intrinsic preference $(\delta)$, price sensitivity $(\alpha)$, software utility $(\gamma)$, and the standard deviation of demand shock $\left(\sigma_{\xi}\right)$. The idea is that the simulated log-odds ratio at the true value of the structural param- eters should be approximately equal to the observed log-odds ratio. When we simulate the log-odds, we use the estimated value of the first stage parameters in computing the choice specific valuation functions. That is, we simulate outcome variables in the second stage based on the relationship estimated in the first stage. In detail, we draw random numbers for $\xi_{j t}^{(r)}$, demand shocks of platform $\mathrm{j}$ at period $\mathrm{t}$ from standard normal distributions. Here, $r=1,2, \ldots, R$ in- 
〈Table 7〉 Log-odds of Market Shares

\begin{tabular}{ccccc}
\hline & \multicolumn{2}{c}{ Sony PlayStation } & \multicolumn{2}{c}{ Nintendo 64} \\
\cline { 2 - 4 } & Estimate & Std. error & Estimate & Std. error \\
\hline Intercept & -3.5242 & 0.0153 & -3.4584 & 0.0232 \\
ySony $^{\text {sintendo }}$ & 11.8477 & 0.7056 & 3.4502 & 1.0409 \\
y $^{2}$ Sony & 4.3025 & 1.2197 & 5.4781 & 1.9147 \\
y $^{\text {Nintendo }}$ & -6.2032 & 3.3483 & 1.5997 & 5.6435 \\
Time & -1.2868 & 7.7446 & 0.7488 & 13.5826 \\
January & -0.0108 & 0.0009 & 0.0053 & 0.0011 \\
February & -0.3448 & 0.0092 & -0.5244 & 0.0138 \\
March & -0.2866 & 0.0083 & -0.4403 & 0.0125 \\
April & -0.2914 & 0.0082 & -0.4578 & 0.0129 \\
May & -0.2181 & 0.0072 & -0.3155 & 0.0101 \\
June & -0.1421 & 0.0051 & -0.2785 & 0.0078 \\
July & -0.1699 & 0.0052 & -0.3162 & 0.0082 \\
August & -0.0866 & 0.0054 & -0.1662 & 0.0087 \\
September & -0.0899 & 0.0066 & -0.1994 & 0.0099 \\
October & -0.0046 & 0.0076 & -0.1470 & 0.0107 \\
November & -0.0260 & 0.0112 & -0.1476 & 0.0162 \\
$\xi_{\text {Sony }}$ & 0.0381 & 0.0065 & -0.0201 & 0.0084 \\
$\xi_{\text {Nintendo }}$ & 0.2030 & 0.0040 & 0.2853 & 0.0056 \\
$\xi_{\text {Sony }}^{2}$ & -0.0338 & 0.0034 & -0.0523 & 0.0067 \\
$\xi^{2}$ Nintendo & 0.0899 & 0.0023 & 0.1243 & 0.0033 \\
$\sigma_{\text {i }}$ & -0.0112 & 0.0028 & -0.2278 & 0.0053 \\
\hline & -3.2036 & 0.0015 & & \\
\hline & & & &
\end{tabular}

dicates simulation draw and $R$ denotes the total number of draws in the simulation. We simulate outcome variables by iterating on the following equations:

$$
\begin{aligned}
& \ln \left(n_{j t}^{(r)}\right)=\Delta\left(y_{j, t+1} ; \widehat{\theta_{n}}\right) \\
& \ln \left(p_{j t}^{(r)}\right)=\Psi\left(y_{j t}, y_{-j t}, z_{t}^{p} ; \widehat{\theta_{p}}\right) \\
& \mu_{j t}^{(r)}=\mathrm{T}\left(y_{j t}, y_{-j t}, \xi_{j t}, z_{t}^{d} ; \widehat{\theta_{\mu}}\right) \\
& s_{j t}^{(r)}=\frac{\exp \left(\mu_{j t}^{(r)}\right)}{1+\sum_{k=1}^{J} \exp \left(\mu_{k t}^{(r)}\right)} \\
& y_{j, t+1}^{(r)}=y_{j t}^{(r)}+\left(1-\sum_{j=1}^{J} y_{j t}^{(r)}\right) \cdot s_{j t}^{(r)} .
\end{aligned}
$$

We then simulate choice-specific values and value of waiting to match the observed market share to the simulated one. We simulate the values by iterating on the equations as follows:

$$
\begin{aligned}
v_{j}(y, \xi, p ; \Lambda, \widehat{\Theta})= & \delta_{j}+w_{j}(f(y, \xi) ; \Lambda, \widehat{\Theta}) \\
& -\alpha p_{j}+\sigma_{\xi} \xi_{j}
\end{aligned}
$$

where $\Lambda=\left(\delta_{\text {Sony }}, \delta_{\text {Nintendo }}, \alpha, \gamma, \sigma_{\xi}\right)$ denotes the set of structural parameters to be estimated in the second stage and $w_{j}(f(y, \xi) ; \Lambda, \widehat{\Theta})$ is the expected present value of software which is si- 
mulated as

$$
w_{j}(f(y, \xi) ; \Lambda, \widehat{\Theta})=\frac{1}{R} \sum_{r=1}^{R} \sum_{t=0}^{T} \beta^{t} u_{j t}^{(r)}\left(y_{j, t+1}^{(r)}\right)
$$

where $u_{j t}^{(r)}\left(y_{j, t+1}^{(r)}\right)=\gamma \exp \left(\Delta\left(y_{j, t+1} ; \widehat{\theta_{n}}\right)\right)=\gamma n_{j t}^{(r)}$. This is the per-period software utility which is assumed to be proportional to the number of available software titles. The simulated value of waiting is the average expected present value of waiting over $\mathrm{R}$ draws.

$$
v_{0}(y, \xi ; \Lambda, \widehat{\Theta})=\frac{1}{R} \sum_{r=1}^{R} \mathrm{Z}^{(r)}
$$

The expected discounted value of waiting for each draw is denoted as

$$
\begin{aligned}
\mathrm{Z}^{(r)}= & \sum_{t=1}^{T} \beta^{t}\left(p_{o t}^{(r)} \tau\left(y_{t}^{(r)}, \xi_{t}^{(r)}\right)\right. \\
& +\sum_{j=1}^{J} p_{j t}^{(r)} \cdot u_{j t}^{(r)}\left(y_{j, t+1}^{(r)}\right)
\end{aligned}
$$

where $p_{o t}^{(r)}=s_{0, t-1}^{(r)} \cdot p_{0, t-1}^{(r)}$ is the probability that a consumer has not purchased any platform up to time $\mathrm{t}$ and $p_{j t}^{(r)}=p_{j, t-1}^{(r)}+s_{j, t-1}^{(r)} \cdot p_{0, t-1}^{(r)}$ is the probability that a consumer has purchased platform $\mathrm{j}$ up to time $\mathrm{t}$. And the term $\tau$ given by

$$
\begin{aligned}
& \tau\left(y_{t}^{(r)}, \xi_{t}^{(r)}\right)=s_{0 t}^{(r)} \cdot E\left(\epsilon_{0 t}\right)+\sum_{j=1}^{J} s_{j t}^{(r)} \\
& \cdot\left(\delta_{j}+u_{j t}^{(r)}\left(y_{j, t+1}^{(r)}\right)-\alpha p_{j t}+\sigma_{\xi} \xi_{j t}+E\left(\epsilon_{j t}\right)\right)
\end{aligned}
$$

is the per-period utility of waiting at time $t$. The expected present discounted value of waiting is the discounted sum of the per-period utility of waiting given that a consumer has not entered the hardware market and the per-period utility of software given that a consumer has adopted one of the platforms prior to time $t$. In our numerical application, we set the discount factor $\beta$ at 0.9 and replicate simulation 60 times $(\mathrm{R}=60)$.

Next, the estimation involves finding the values of structural parameters at which the distance between the simulated log-odds of market shares and the observed ones is minimized. Again, the structural parameters $\Lambda=\left(\delta_{\text {Sony }}\right.$, $\left.\delta_{\text {Nintendo }}, \alpha, \gamma, \sigma_{\xi}\right)$ include intrinsic preferences for each platform, marginal disutility of price, marginal utility of software titles and standard deviation of demand shocks. The distance between the observed log-odds of market shares and the simulated ones is given by

$$
\begin{aligned}
Q_{j t}\left(\Lambda_{0}, \widehat{\Theta}\right)= & \mu_{j t}-\left(v_{j}\left(y, \xi, p ; \Lambda_{0}, \widehat{\Theta}\right)\right. \\
& \left.-v_{0}\left(y, \xi ; \Lambda_{0}, \widehat{\Theta}\right)\right)
\end{aligned}
$$

where $\Lambda_{0}$ is the true parameter values. The minimum distance estimator is obtained by solving the minimization problem, i.e.,

$$
\Lambda_{M D}=Q(\Lambda, \widehat{\Theta})^{\prime} W Q(\Lambda, \widehat{\Theta})
$$

where $W$ is a positive semi-definite weight matrix. We use an identity matrix for the weight. The estimation results are provided in Figure 1, Figure 2 and Figure 3. Figure 1 depicts the 
estimated game provision and the observed game provision. Figure 2 displays the observed prices along with fitted prices for hardware. Finally Figure 3 displays the log-odds. The MAPDs of game provision are $11.38 \%$ and 23.54 for Playstation and Nintendo 64 respectively. For prices, the MAPDs are $8.48 \%$ and $8.68 \%$. And for log-odds, the MAPDs are 5.81\% and $6.74 \%$. The model appears to capture well the observed market outcomes up to random fluc-

〈Figure 1〉In-Sample Fit : Game Provision
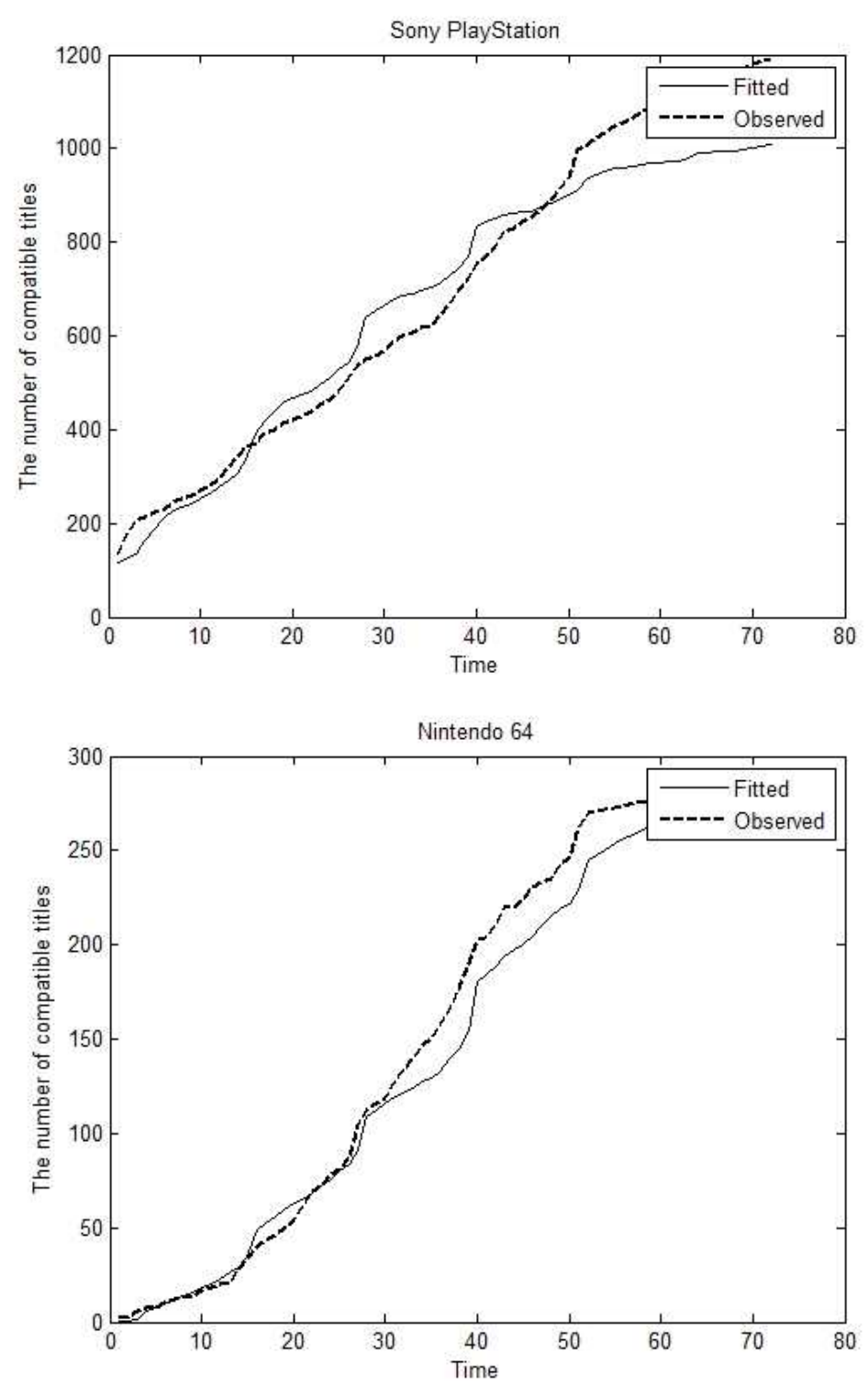

Measuring the Impact of Competition on Pricing Behaviors in a Two-Sided Market 53 
〈Figure 2〉 In-Sample Fit : Price
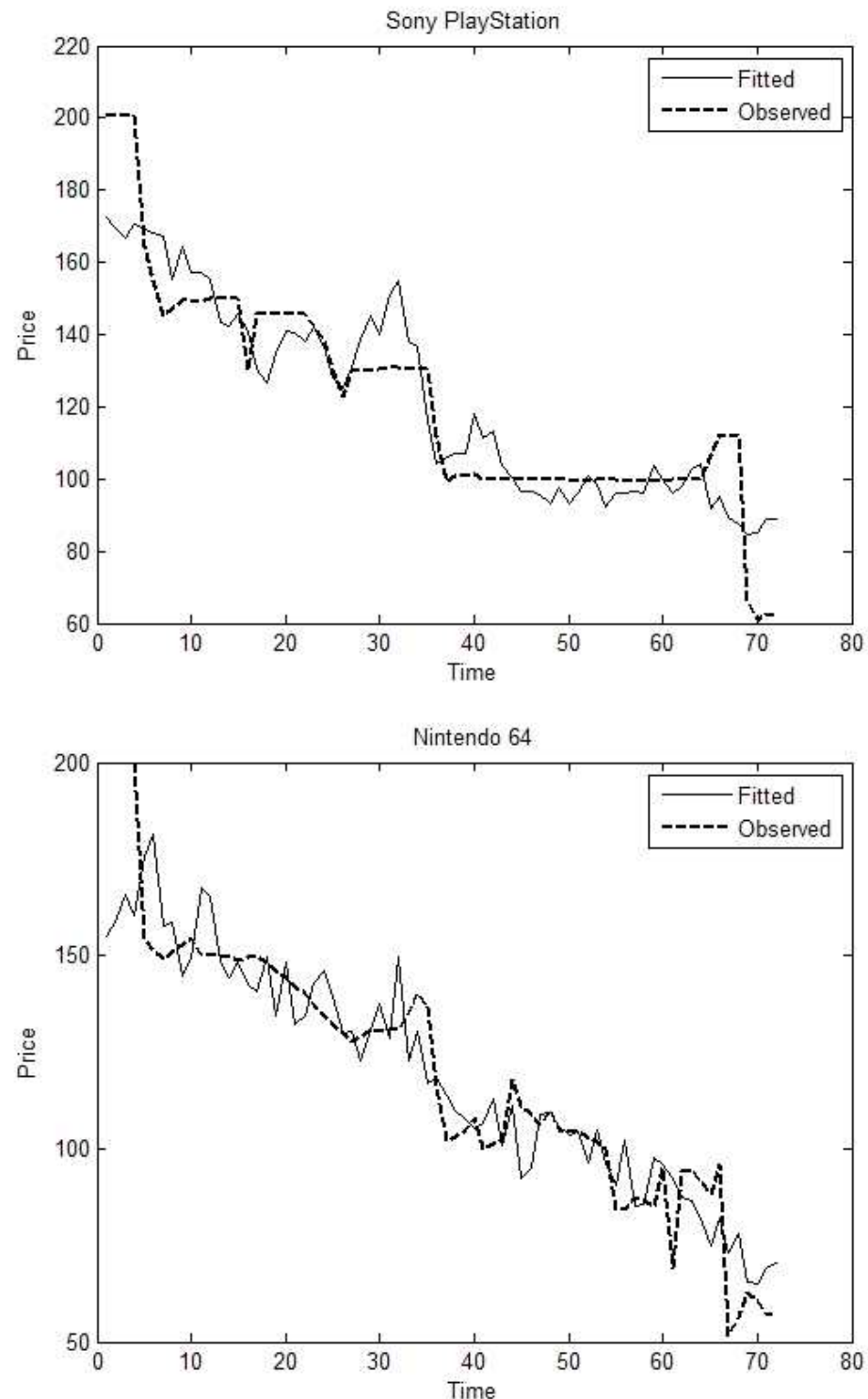

tuations, especially for prices and log-odds.

The estimates of the structural parameters are presented in Table 8 . We do not find any significant difference between the intrinsic preference for Sony and for Nintendo. Marginal utility of income is estimated to be significant. The indirect network effect, as reflected in the software utility $\gamma$, is estimated to be positive although its standard error is very large. 
〈Figure 3〉In-Sample Fit : Log-odds of Market Share
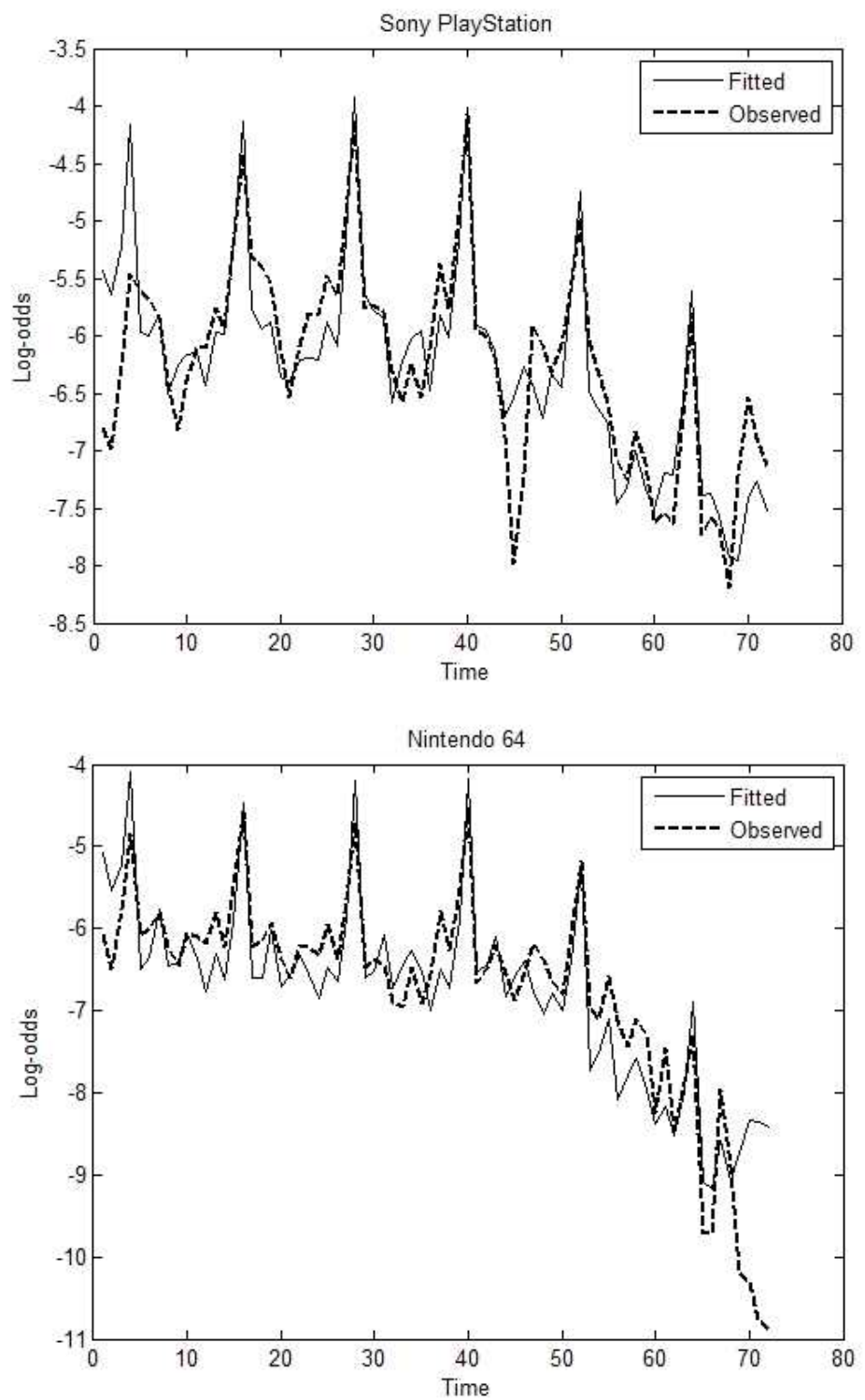

$\langle$ Table 8〉 Structural Parameters

\begin{tabular}{ccc}
\hline & Estimate & Standard error \\
\hline$\delta_{\text {Sony }}$ & -0.4972 & 6.9260 \\
$\delta_{\text {Nintendo }}$ & -0.4454 & 0.4989 \\
$\alpha$ & 0.0192 & 0.0005 \\
$\gamma$ & 0.0061 & 0.1090 \\
$\sigma_{\xi}$ & 0.0511 & 0.0548 \\
\hline
\end{tabular}

Measuring the Impact of Competition on Pricing Behaviors in a Two-Sided Market 55 


\subsection{Equilibrium Prices}

The whole point of this paper is to investigate the impact of competition on pricing behavior. Since the data is obtained from an industry under duopoly competition, the observed prices include the competitive effects. Now we are ready to conduct counterfactual experiments as we have estimated structural parameters. We compute the expected prices for the hypothetical monopoly case where two companies are merged and compare such counterfactual prices with observed prices to identify the impact of competition on pricing.

Given model parameters, we numerically compute equilibrium hardware prices through value function iteration. The algorithm iterates expected software value, choice-specific value, value of waiting and new pricing policies until value functions change little. The pricing strategy that corresponds to the converged value function is the policy function. The detailed computation procedure is as follows:

Step 1. We first discretize the state spaces for installed hardware base, demand shocks and pricing policies of each firm. Installed hardware base in the state space is discretized in $\mathrm{Y}$ grids and each grid consists of two elements, each of which is Sony PlayStation's installed base and Nintendo 64's installed base. The sum of the installed hardware base on each grid is smaller than 1 by definition. Demand shocks are discretized based on N-point Gauss-Hermite quadrature rule. We integrate out demand shocks in the subsequent steps by evaluating the integrand at the quadrature nodes. Pricing policies of each firm are discretized into P uniformly spaced grids, respectively.

Step 2. We take initial guesses on the consumers' expectations on the evolution of the installed hardware base $f^{e}\left(y_{t}, \xi_{t}\right)$ and pricing policies $\sigma_{j}^{e}\left(y_{t}, \xi_{j t}\right)$. We assume reasonable initial values by reflecting the relationship between the outcome variables to be evolved and the state variables from the data. Note that the initial guesses should be one of the discretized grids. We take the discretized values which have the minimum distances from the expected outcomes from the data as initial values.

Step 3. We compute $\omega_{j}\left(y_{t+1}\right)$, the expected present value of software titles using equation (5) given $f^{e}\left(y_{t}, \xi\right)$. The per-period utility of software $u_{j}\left(y_{j, t+1}\right)=\gamma \cdot \exp \left(\Delta\left(y_{j, t+1}\right)\right)$ is calculated using discretized state grids, the estimated relationship between installed hardware base and software variety provided in Table 5 and the estimated structural parameters provided in Table 8. Note that the integral over $\xi$ space is the weighted average of the integrand over the discretized quadrature nodes. We iterate $\omega_{j}\left(y_{t+1}\right)$ on the contraction mapping until both $\omega_{\text {Sony }}\left(y_{t+1}\right)$ and $\omega_{\text {Nintendo }}\left(y_{t+1}\right)$ converge.

Step 4. Based on $\omega_{j}\left(y_{t+1}\right)$ computed in step 
3 and structural parameters provided in Table 8, we calculate choice-specific values, $\nu_{j}\left(y_{t}, \xi_{t}, p_{t}\right)$, from the equation (6).

Step 5. We calculate $\nu_{0}\left(y_{t}, \xi_{t}\right)$, value of waiting from the equation (7) by iterating the value on the contraction mapping. The equation is equal to

$$
\begin{aligned}
& v_{0}\left(\mathrm{y}_{\mathrm{t}}, \xi_{\mathrm{t}}\right)=\beta \int \ln \left(\exp \left(v_{0}\left(\mathrm{y}_{\mathrm{t}+1}, \xi_{\mathrm{t}}\right)\right)\right. \\
& +\sum_{j=1}^{J} \exp \left(v_{\mathrm{j}}\left(\mathrm{y}_{\mathrm{t}+1}, \xi, \sigma^{\mathrm{e}}\left(\mathrm{y}_{\mathrm{t}+1}, \xi_{\mathrm{j} t}\right)\right)\right) \phi(\xi) \mathrm{d}(\xi)
\end{aligned}
$$

The above equation utilizes the property of Type I Extreme Value distribution. Note that the integrand consists of value of waiting and choice-specific values evaluated at time $t+1$, not at time t. We iterate $\nu_{0}\left(y_{t}, \xi_{t}\right)$ on the contraction mapping until the value converges.

Step 6. We calculate and update the market share from the equation (8) based on the updated values from step 4 and 5 . The installed hardware base evolves according to the equation (9). We take the value on the discretized space as the new installed base which has the minimum distance from the updated installed hardware base.
Step 7. We compute the per-period profit function and the corresponding Bellman equation from the equation (11) and (12) for the oligopoly case and (14) and (15) for the monopoly case on each value of discretized pricing policies. Thus the Bellman equation computed has dimensions that are $\mathrm{P}$ times greater than the dimensions of the values and Bellman equations calculated in the previous steps. Note that $q_{j}\left(y_{j, t+1}\right)$ is estimated from the data. Since we control for falling marginal costs by including exogenous variables, we assume constant marginal $\operatorname{costs}^{3)}$ in the empirical model.

Step 8. We find new pricing policies $\sigma_{j}\left(y, \xi_{j}\right)$ that maximize the Bellman equation converged in step 7 on each state space grid and compute the maximized Bellman equation corresponding to the pricing policies of each standard from the equation (13) for the oligopoly case and (15) for the monopoly case.

Step 9. We update pricing policies as $p_{j}=$ $\sigma_{j}\left(y, \xi_{j}\right)$ and consumers' expectations about the installed hardware base as $y=f(y, \xi)$. We iterate from step 3 to step 7 until the policy function converges. Here, we use the modified Newton-Raphson method, ${ }^{4)}$ one of the damp-

2) Dubé, Hitsch and Chintagunta(2010) estimate the relationship between the installed hardware base and the number of software titles sold as $\log \left(q_{j t}\right)=\varrho+\varphi_{\mathrm{j}} \log \left(\mathrm{y}_{\mathrm{j}, t+1}\right)$ from CES preference model. We use the parameters reported to estimate the software sales.

3) Marginal production costs are set to be $\$ 147$ (Sony PlayStation) and $\$ 122$ (Nintendo 64) and royalty fees are assumed to be $\$ 9$ (Sony PlayStation) and $\$ 18$ (Nintendo 64) based on Liu(2010) and Dubé, Hitsch and Chintagunta(2010). We test the robustness of the results with a different cost specification in the appendix.

4) $\sigma_{\mathrm{j}}{ }^{(k+1)}\left(\mathrm{y}, \xi_{\mathrm{j}}\right)=\mathrm{a} \cdot \sigma_{\mathrm{j}}{ }^{(k+1)}\left(\mathrm{y}, \xi_{\mathrm{j}}\right)+(1-\mathrm{a}) \cdot \sigma_{\mathrm{j}}{ }^{(k)}\left(\mathrm{y}, \xi_{\mathrm{j}}\right)$ where $a \in[0,1]$ and the closer $a$ is to 0 , the more likely the function is to converge. 
ing schemes to facilitate convergence since the multi-agent iteration algorithms may have multiple equilibria and some of them do not converge but oscillate.

We use a discount factor of 0.9 for both consumers and firms. We examine a symmetric competition case where Sony and Nintendo launch their products at the same time at the beginning period of this analysis and share the same demand functions. Our main goal is the comparison of market outcomes between with and without competition among manufacturers. We compare the price policies, price patterns and price levels in oligopoly market to those in the merged case. In the merged case, we use the per-period profit function and Bellman equation as shown in equation (14) and (15) but hold all other model primitives same as in the observed duopoly market. Doing so requires an assumption that parameters are equal across two competitive regimes. For the demand side, it is very natural to assume that consumer preferences and sensitivities are the same across two hypothetical competitive structures. For the supply, it requires a more demanding assumption that the cost function is the same between two competitive structures. To be consistent with these assumptions, the parameters we have should be policy-invariant parameters. If parameters are policy-dependent, then counterfactual comparison is infeasible. That is why researchers rely on structural modeling approach to have policy-invariant parameters, as opposed to what reduced-from models would do (Chintagunta, Erdem, Rossi, and Wedel 2006). Our study also has to rely heavily on microfoundations in order to have a structural model.

Figure 4 and Figure 5 exhibit equilibrium pricing policies at each discretized point of hardware installed base in duopoly and monopoly market, respectively. Here $y_{S}$ stands for installed hardware base of Sony PlayStation and $y_{N}$ represents that of Nintendo 64. These figures depict the equilibrium pricing pattern as a function of installed base.

While it is possible to display visually the optimal pricing, those figures appear to be very difficult to interpret. So we depict the expected price paths in Figure 6. The paths are conditional on cases where consumers and firms make decisions at the monthly level, both standards sell as many products as their observed sales by the end of $\mathrm{T}=72$ and the rates of increase in their installed base remain constant afterwards. We simulate the prices for 100 months. The expected pricing policies are functions of installed hardware base and demand shocks. Here we generate 60 simulations of the random transitions of demand shocks and average the realized prices from the simulations. In addition, we generate simulations of the market evolution at the same time. The evolution of the market needs to be simulated since the software provision function, the no-purchase value function and the Bellman equations in the supply side depend on the installed hardware base 
〈Figure 4〉 Equilibrium Pricing Policies in Duopoly Market
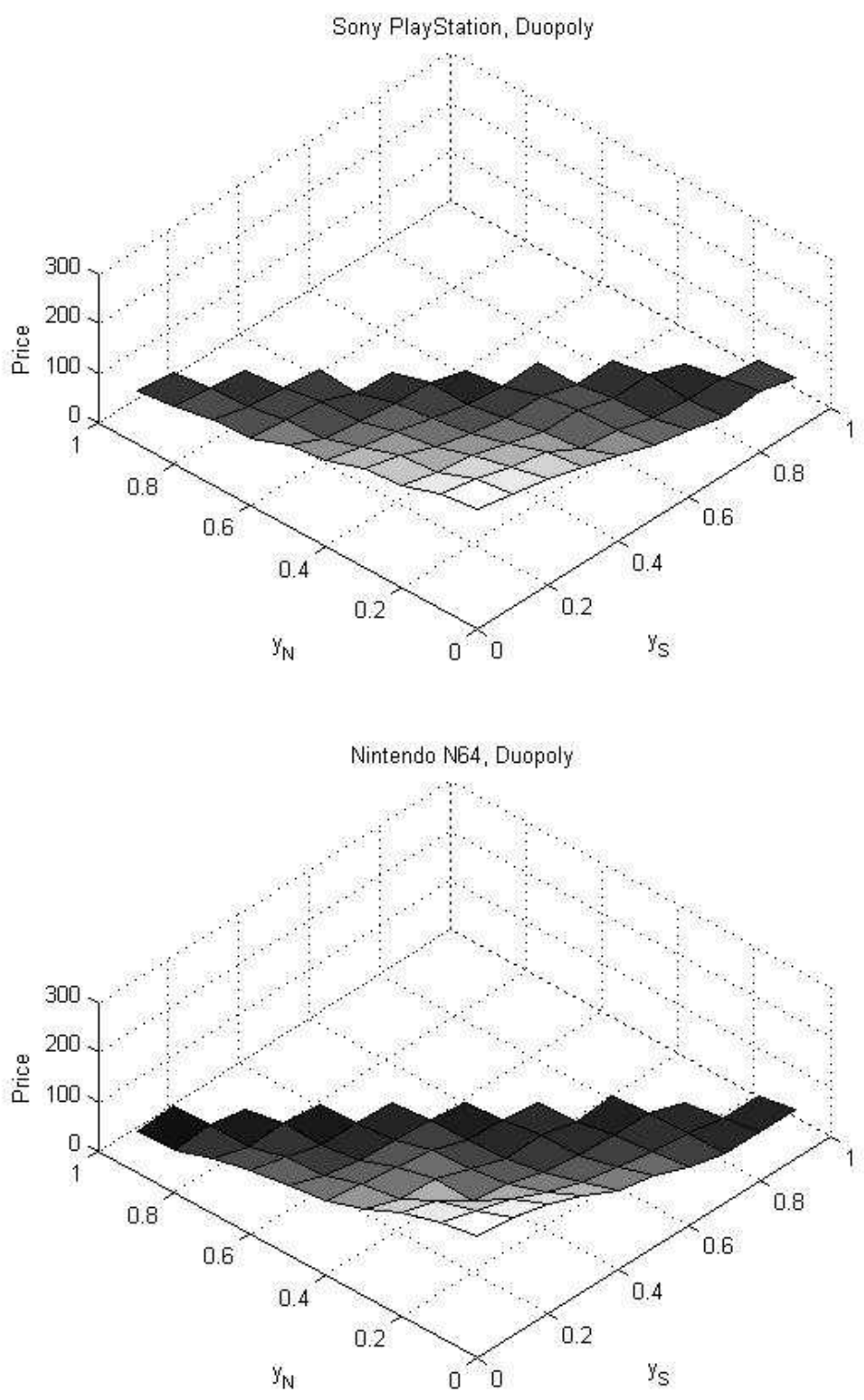

in the subsequent period.

The temporal patterns appear similar for both standards and for both industry structures. The manufacturers bring down their product prices over time. Notably, the price levels dif- ferentiate duopoly and monopoly markets. The firms would not lower prices enough unless they do not have competition in the platform market. When firms compete, they focus on capturing initial advantage and enticing more 
〈Figure 5〉 Equilibrium Pricing Policies in Monopoly Market
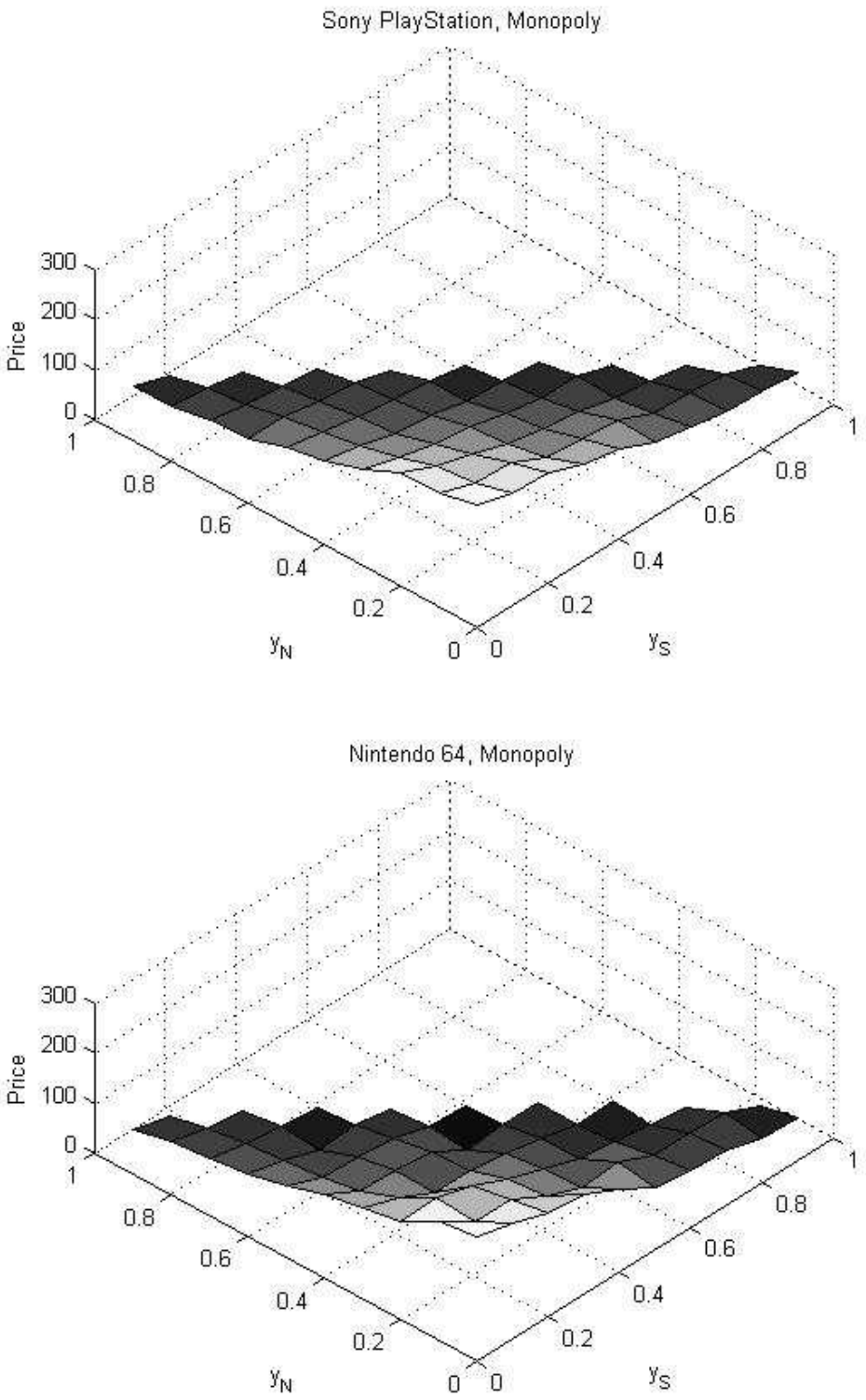

consumers to join their networks by setting lower prices. Note that a two-sided market is distinguished from a traditional market since consumers' adoption decisions are affected by indirect network effects. That is, a standard with initial advantage gets positive feedbacks from its consumers and its software suppliers. The initial advantage leads to more software variety for the standard than its competitors. Hence, more consumers will purchase the plat- 
〈Figure 6〉 Expected Price Paths
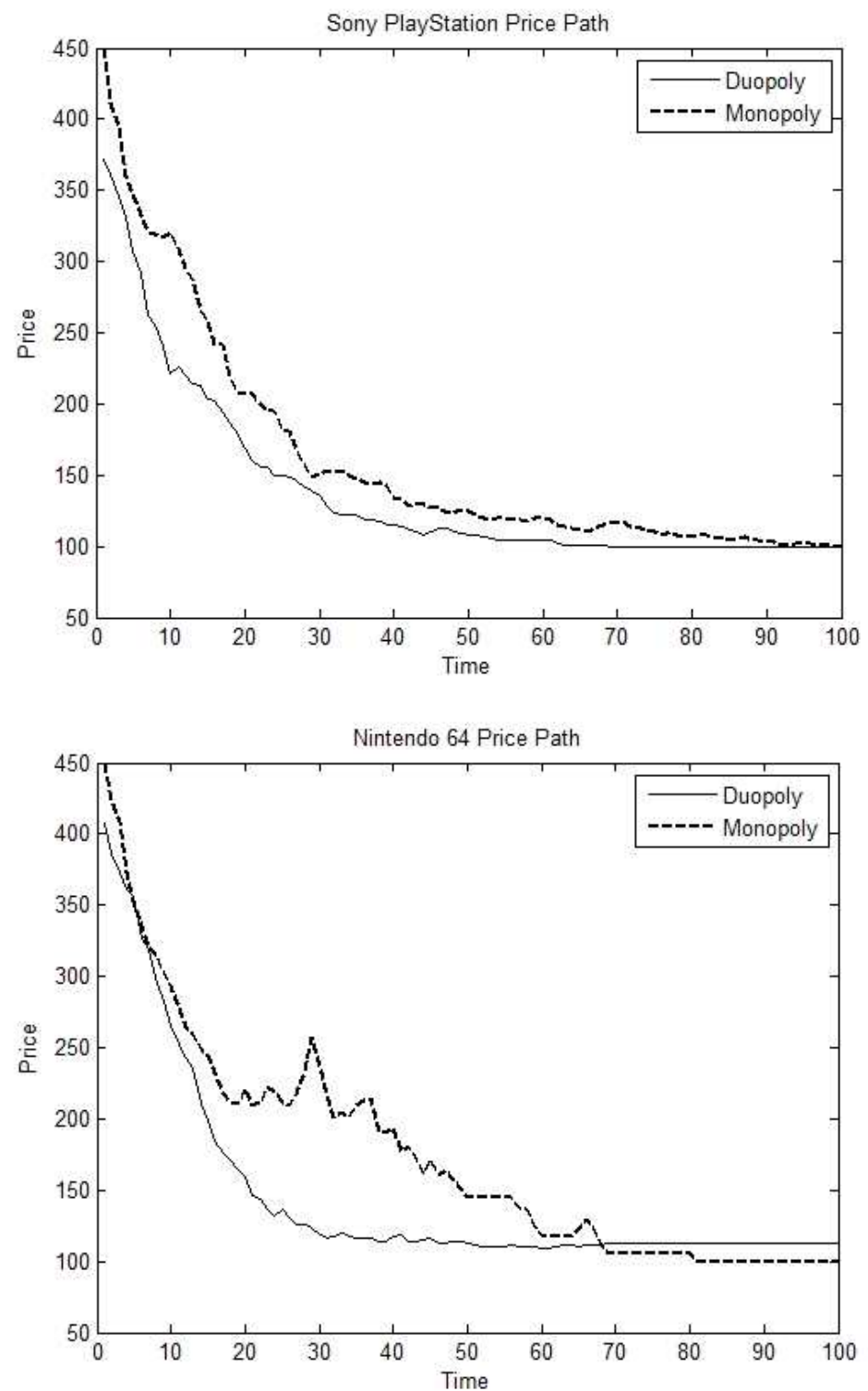

form than other standards in the subsequent of the standard. Given this, competing platperiod. This asymmetric adoption rate reinforces forms have a strong incentive to invest during the leadership of the standard, helps the platrelatively early periods to accumulate installed form's network to create a virtuous cycle and bases. The investment incentive is realized in finally leads to market concentration in favor the form of lower prices. 
〈Figure 7〉 Expected Software Provision
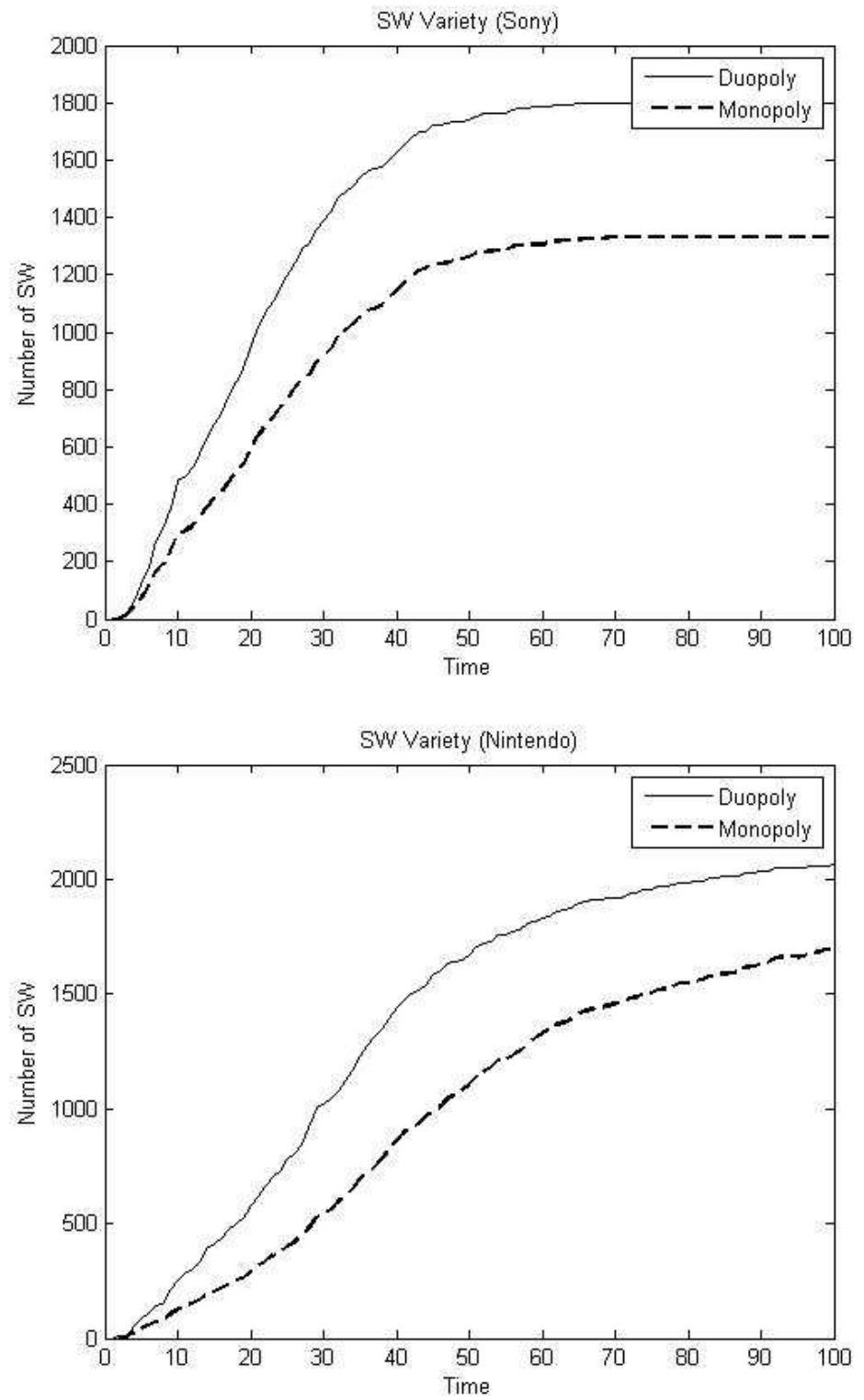

However, the merged firm in the hypothetical monopoly does not have to take account of the initial advantage or the risks that consumers might prefer other standards over its product at the introduction stage. It has been well demon- strated that in static models such as Nevo (2000) and Dube (2005) joint profit maximization in a monopoly clearly results in a different payoff from that obtained in independent profit maximization in a competitive market. The 
price differential between two competitive regimes in static model settings comes mostly from the ability of the monopoly firm to internalize consumer switching behaviors across brands. In a dynamic setting as in our model, such internalization extends to indirect network externalities. The internalization of consumer switching (consumers' purchase of a platform at the expense of other platform) occurs not only at the immediate market share level but also at the software provision level. Because of the positive feedback inherent in a two-sided market, competing platforms have an incentive to behave aggressively to increase the indirect network (e.g., the number of compatible software titles). But the monopoly firm does not have to be aggressive as it internalizes switching that occurs due to the availability of complements. Thus the monopoly firm has much less incentive to invest. Rather it has an incentive to harvest by charging relatively higher prices. So the price gaps between the duopoly and the monopoly are highlighted in relatively early periods. Since the monopoly would invest less, the complement market (software title market) grows at a much slower rate as shown in Figure 7. This result is robust to a different cost specification and the marginal costs are simulated in the appendix.
In addition to the visual displays, we also quantify the impact of competition on dynamic pricing of platforms as the average percentage changes in prices and in consumers' values from duopoly to monopoly market for each standard. The percentage change is computed by the ratio of the difference between the values in $\mathrm{du}^{-}$ opoly market and those in monopoly market to the values in duopoly market. As shown in Table 9 , the hardware prices go up by $14.8 \%$ for Sony PlayStation and by $21.8 \%$ for Nintendo 64 on average when we eliminate the competition among platforms exogenously. The merged manufacturer increases Nintendo 64's price more than Sony PlayStation's price in terms of percentage because the supplier of Nintendo 64 in the duopoly market sets relatively lower prices to capture initial advantage so that it can benefit from higher royalty fees from game developers.

Note that Nintendo 64 collects higher royalty fee for each software title sold than Sony PlayStation does in the empirical model. The competing firms in the duopoly market focus on different competitive advantages. The removal of competition would result in a decrease of consumer value by $43.1 \%$ on average. The increase in price and the consequent decrease in the variety of software titles in the market

〈Table 9〉 Percentage Change in Price and Consumer Value

\begin{tabular}{cccc}
\hline & Sony Price & Nintendo Price & Customer Value \\
\hline Mean & 14.8 & 21.8 & -43.1 \\
Median & 14.0 & 10.2 & -34.7 \\
\hline
\end{tabular}


would lead to lower consumers' surplus.

\section{Conclusion}

This study provides a framework to examine the impact of the competitive structure on firms' optimal pricing strategies in a two-sided market. We calibrate the demand model that incorporates indirect network effects, consumers' forward-looking behaviors and manufacturers' dynamic competition by estimating parameters that minimize the distance between simulated log-odds of market share and observed ones. We utilize the estimation results in conducting counterfactual analyses for the effect of competition.

We quantify the impact of exogenously determined competition structure on pricing as the percent changes in prices and consumer values for each platform. The empirical application of the model to the U.S. 32/64 bit video game console category reveals that firms set higher prices in the absence of competition by $14.8 \%$ and $21.8 \%$ for Sony PlayStation and Nintendo 64, respectively. Such removal of competition would result in a reduction in consumer value by $43.1 \%$. This result is attributed to the distinct property of a two-sided market that competing firms tend to set low prices particularly at the initial period to attract consumers at the introductory stage and to reinforce their own networks and eventually to dominate the market.

Future research in various directions to relax the assumptions in this research will help shed light on the related topics. First, we here do not take account of first-mover advantage. Sony entered the video game console market with the new generation of PlayStation one year earlier than Nintendo did. Since we intend to analyze the effect of firms' dynamic decisions under various market structures, we only consider the periods when both firms sell the products in the market. If the first-mover advantage is taken into account in the model, the standard that pioneers the market will have the initial installed base advantage. This initial advantage causes more software developers to supply game titles compatible with the standard. Thus more consumers will engage in the standard and the positive feedback will strengthen the market leadership of the pioneering platform. This leadership is due to indirect network effects since consumers prefer to lock in the platform's network. Such initial advantage in a two-sided market will make potential entrants reluctant to set high prices in the market and the impact of exogenously determined competition in the market will differ from the results in the symmetric market investigated in our research.

Another area for future research is to capture indirect network effects in terms of software contents or quality. For instance, there are killer applications in smartphone industry that induces consumers to purchase the specific carriers. 
We here only consider the software variety to explain the source of indirect network effects since the contents is difficult to measure and incorporate in the model. However, if some of the applications or software titles take a lot of fractions in the market and have a great impact on consumers' purchase decisions, the model can provide the analysis on the role of game contents and the different values on the impact of competition among platforms in the market.

〈Received July 26. 2013〉

〈1st Revised January 10. 2014〉

〈2nd Revised January 20. 2014〉

〈Accepted January 28. 2014〉

\section{References}

Ackerberg, Daniel A. 2003. Advertising, Learning, and Consumer Choice in Experience Good Markets: An Empirical Examination. International Economic Review. 44(3) 10071040.

Argentesi, Elena, Lapo Filistrucchi. 2007. Estimating Market Power in a Two-Sided Market: The Case of Newspapers. Journal of Applied Econometrics. 22(7) 1247-1266.

Armstrong, Mark. 2006. Competition in Twosided Markets. RAND Journal of Economics. 37(3) 668-691.

Berry, S., J. Levinsohn, and A. Pakes (1995). Automobile Prices in Market Equilibrium.
Econometrica, 841-890.

Caillaud, Bernard, Bruno Jullien. 2003. Chicken and Egg: Competition Among Intermediation Service Providers. RAND Journal of Economics. 34(2) 309-328.

Chintagunta, Pradeep, Tülin Erdem, Peter E. Rossi, Michel Wedel. 2006. Structural Modeling in Marketing: Review and Assessment. Marketing Science. 25(6) 604-616.

Coughlan, Peter J. 2001. Competitive Dynamics in Home Video Games $(\mathrm{K})$ : PlayStation vs. Nintendo64. HBS case 9-701-101. Harvard Business School, Boston.

Crisfield, M. A. 1979. A Faster Modified NewtonRaphson Iteration. Computer Methods in Applied Mechanics and Engineering. 20(3) 267-278.

Dubé, Jean-Pierre. 2005. Product Differentiation and Mergers in the Carbonated Soft Drink Industry. Journal of Economics and $\mathrm{Ma}^{-}$ nagement Strategy. 14(4) 879-904.

Dubé, Jean-Pierre H., Günter J. Hitsch, Pradeep K. Chintagunta. 2010. Tipping and Concentration in Markets with Indirect Network Effects. Marketing Science. 29(2) 216-249.

Erdem, Tülin, Michael P. Keane. 1996. Decisionmaking under Uncertainty: Capturing Dynamic Brand Choice Processes in Turbulent Consumer Goods Markets. Marketing Science. 15(1) 1-20.

Erdem, Tülin, Susumu Imai, Michael P. Keane. 2003. Consumer Price and Promotion Ex- 
pectations: Capturing Consumer Brand and Quantity Choice Dynamics under Price Uncertainty. Quantitative Marketing and Economics. 1(1) 5-64.

Erdem, Tülin, Michael P. Keane, T. Sabri Öncü, Judi Strebel. 2005. Learning about Computers: An Analysis of Information Search and Technology Choice. Quantitative Marketing and Economics. 3(3). 207-247.

Evans, David S., Richard Schmalensee. 2007. The Industrial Organization of Markets with Two-sided Platforms. Competition Policy International. 3(1) 151-179.

Godes, David, Elie Ofek, Miklos Sarvary. 2009. Content vs. Advertising: The Impact of Competition on Media Firm Strategy. Marketing Science. 28(1) 20-35.

Gönül, Füsun, Kannan Srinivasan. 1996. Estimating the Impact of Consumer Expectations of Coupons on Purchase Behavior: A Dynamic Structural Model. Marketing Science. 15(3) 262-279.

Goettler, Ron, Brett Gordon. 2011. Does AMD Spur Intel to Innovate More? Journal of Political Economy. 119(6) 1141-1200.

Gordon, Brett. 2009. A Dynamic Model of Consumer Replacement Cycles in the PC Processor Industry. Marketing Science. 28(5) 846-867.

Gupta, Sachin, Dipak C. Jain, Mohanbir S. Sawhney. 1999. Modeling the Evolution of Markets with Indirect Network Externalities: An Application to Digital Television.
Marketing Science. 18(3) 396-416.

Hendel, I. (1999). Estimating Multiple-Discrete Choice Models: An Application to Computerization Returns. The Review of Economic Studies, 66(2), 423-446.

Hendel, Igal, Aviv Nevo. 2006. Measuring the Implications of Sales and Consumer Inventory Behavior. Econometrica. 74(6) 16371673.

Hitsch, Günter J. An Empirical Model of Optimal Dynamic Product Launch and Exit under Demand Uncertainty. Marketing Science. 25(1) 25-50.

Hotz, V. Joseph, Robert A. Miller. 1993. Conditional Choice Probabilities and the Estimation of Dynamic Models. Review of Economics and Statistics. 60(3) 497-529.

Judd, Kenneth L. 1998. Numerical Methods in Economics. MIT Press, Cambridge, MA.

Kaiser, Ulrich, Julian Wright. 2006. Price Structure in Two-sided Markets: Evidence from the Magazine Industry. International Journal of Industrial Organization. 24(1) 1-28.

Kaiser, Ulrich, Minjae Song. 2009. Do Media Consumers Really Dislike Advertising? An Empirical Assessment of the Role of $\mathrm{Ad}^{-}$ vertising in Print Media Markets. International Journal of Industrial Organization. 27(2) 292-301.

Katz, Michael L., Carl Shapiro. 1985. Network Externalities, Competition, and Compatibility. The American Economic Review. 75(3) 424-440. 
Kim, Youngju, Jaehwan Kim. 2013. Movie Choice under Joint Decision: Reassessment of Online WOM Effect, Asia Marketing Journal, 15 (1), 155-168

Kim, Kyung Jin., Inseong Song. 2012. The Impact of Horizontal Merger between Manufacturers on Channel Pricing Behaviors. Seoul Journal of Business. 18(1). 125-154

Liu, Hongju. 2010. Dynamics of Pricing in the Video Game Console Market: Skimming or Penetration? Journal of Marketing Research. 47(3) 428-443.

Markovich, Sarit, Johannes Moenius. 2009. Winning while Losing: Competition Dynamics in the Presence of Indirect Network Effects. International Journal of Industrial Organization. 27(3) 346-357.

Mehta, Nitin, Surendra Rajiv, Kannan Srinivasan. 2003. Price Uncertainty and Consumer Search: A Structural Model of Consideration Set Formation. Marketing Science. 22(1) 58-84. Nair, Harikesh, Pradeep Chintagunta, Jean-Pierre Dubé. 2004. Empirical Analysis of Indirect Network Effects in the Market for Personal Digital Assistants. Quantitative Marketing and Economics. 2(1) 23-58.

Nair, Harikesh. 2007. Intertemporal Price Discrimination with Forward-looking Consumers: Application to the U.S. market for Console Video-games. Quantitative Marketing and Economics. 5(3) 239-292.

Nevo, Aviv. 2000. Mergers with Differentiated Products: The Case of the Ready-to-Eat
Cereal Industry. RAND Journal of Economics. 31(3) 395-421

Park, Sangin. 2004. Quantitative Analysis of Network Externalities in Competing Technologies: The VCR Case. Review of ECOnomics and Statistics. 86(4) 937-945.

Petrin, Amil. And Kenneth Train 2010. A Control Function Approach to Endogeneity in Consumer Choice Models. Journal of Marketing Research. 47(1) 3-13.

Rochet, Jean-Charles, Jean Tirole. 2003. Platform Competition in Two-sided Markets. Journal of the European Economic Association. 1(4) 990-1029.

Rochet, Jean-Charles, Jean Tirole. 2006. Twosided Markets : A Progress Report. RAND Journal of Economics. 37(3) 645-667.

Rust, John. 1987. Optimal Replacement of GMC Bus Engines: An Empirical Model of Harold Zurcher. Econometrica. 55(5) 999-1033.

Song, Inseong, Pradeep Chintagunta. 2003. A Micromodel of New Product Adoption with Heterogeneous and Forward-looking Consumers: Application to the Digital Camera Category. Quantitative Marketing and Economics. 1(4) 371-407.

Sun, Baohong, Scott A. Neslin, Kannan Srinivasan. 2003. Measuring the Impact of Promotions on Brand Switching When Consumers are Forward Looking. Journal of Marketing Research. 40(4) 389-405.

Sun, Baohong, Jinhong Xie, H. Henry Cao. 2004. Product Strategy for Innovators in 
Markets with Network Effects. Marketing Science. 23(2) 243-254.

Sun, Baohong. 2005. Promotion Effect on Endogenous Consumption. Marketing Science. 24(3) 430-443.

Tellis, Gerard J., Eden Yin, Rakesh Niraj. 2009. Does Quality Win? Network Effects versus Quality in High-tech Markets. Journal of Marketing Research. 46(2) 135-149.
Train, Kenneth E. 2002. Discrete Choice Methods with Simulation, Cambridge University Press, Cambridge.

Tucker, Catherine, Juanjuan Zhang. 2010. Growing Two-Sided Networks by Advertising the User Base: A Field Experiment. Marketing Science. 29(5). 809-814. 


\section{〈Appendix〉}

We control for declining costs with exogenous cost-shift variables and assume constant marginal costs in price simulation. Here we estimate parameters for declining costs to verify the robustness of the result. Liu(2010) specifies the cost function as

$$
C_{j t}\left(Q_{j t}\right)=c_{j t} Q_{j t}+F_{j t}
$$

where $Q_{j t}$ is hardware sales for standard $\mathrm{j}, c_{j t}$ is marginal cost and $F_{j t}$ is fixed cost. We assume that video game console manufacturers do not incur fixed costs and marginal costs decrease exogenously over time. Following Liu(2010), the marginal costs are assumed to decline exponentially over time which is denoted as

$$
c_{j t}=a_{j} \exp \left(-b_{j} t\right)
$$

\section{〈Figure A.1〉 Expected Cost Path}

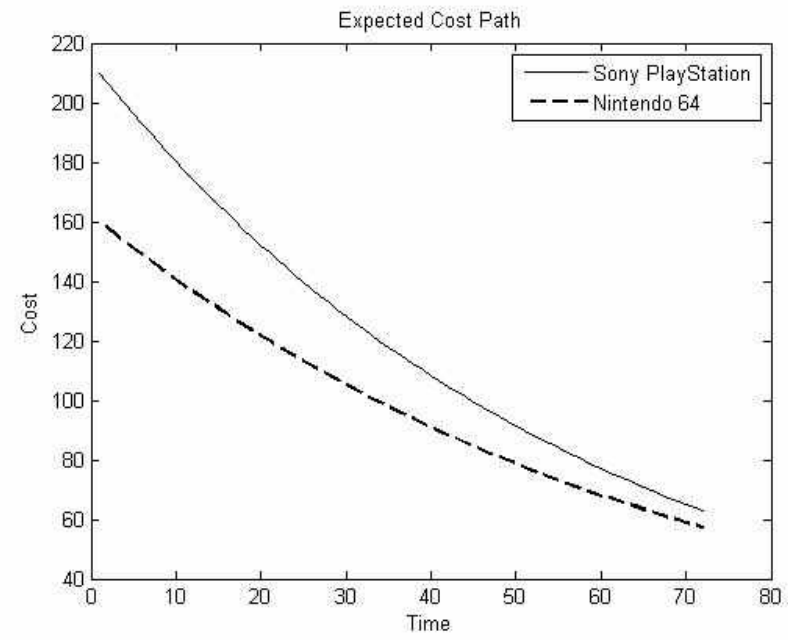

Industry reports on video game console market make comments on marginal costs at a few time periods. We use the available data to compute the expected cost path throughout the observed periods and display the result in Figure A.1. We estimate demand parameters and simulate price paths again using the estimated costs. Although we do not report the full analyses here, the merged firm sets higher prices than each manufacturer does in the duopoly market. That is, the results are robust to the cost specification. 